\title{
LA SERIEDAD DE LOS DERECHOS
}

\author{
MANUEL MARTÍNEZ SOSPEDRA \\ Profesor Titular de Derecho Constitucional, UVEG \\ Profesor Ordinario de Derecho Constitucional, CUEJ-CEU
}




\section{SUMARIO}

1. Antecedentes. 2. Historia de la redacción. 3. El discurso del art. 10.1. 4. LA DIGNIDAD DE LA PERSONA. a) El problema de la "persona». b) La dignidad. c) La dignidad de la persona en la jurisprudencia del TC. 5 . LOS DERECHOS: INHERENCIA E INVIOLABILIDAD. a) Los derechos inherentes e inviolables. b) Limitación del poder del Estado y contenido esencial. 6. EL LIBRE DESARROLLO de LA PERSONALIDAD. 7. Fronteras. 8. Los derechos fundamentales COMo ORDENAMIENTO OBJetIVO. 9. LA CLÁUSULA HeRMEnÉUtica. a) El problema del ámbito. b) Las normas de referencia. c) La significación de la cláusula. 


\title{
LA SERIEDAD DE LOS DERECHOS
}

POR

\author{
MANUEL MARTÍNEZ SOSPEDRA \\ Profesor Titular de Derecho Constitucional, UVEG \\ Profesor Ordinario de Derecho Constitucional, CUEJ-CEU
}

\section{ANTECEDENTES}

El actual artículo 10 de la Constitución desempeña un papel capital en el sistema de derechos que la propia ley fundamental configura desde el momento que contiene los principios que organizan dicho sistema, y hacen que el mismo sea tal, fijan reglas hermenéuticas de uso jurídicamente necesario y configuran el estatuto de los derechos fundamentales en el ordenamiento jurídico español.

El artículo constitucional que comentamos no tiene, en rigor, precedente alguno en el Derecho Constitucional histórico español, viniendo a constituir una innovación constitucional radical respecto de la tradición histórica misma. Del mismo modo carece de cualquier antecedente el apartado segundo del citado art. $10 \mathrm{CE}$, que no sólo no tiene precedente en la tradición histórica, sino que no tiene paralelo en las constituciones europeas de nuestro entorno. En contrapartida el apartado primero sí tiene un claro precedente en el constitucionalismo de nuestro entorno: los arts. 1 y 2.1. de la Ley Fundamental de Bonn, y ello hasta un punto tal que no sería exagerado señalar que el precedente germano es el antecedente directo del art. 10.1. Tal hecho no es tan visible en el texto definitivo, pero resulta claro a la vista de los trabajos de la Ponencia Constitucional. En cuanto a la cláusula del art. 10.2. la misma no aparece en los trabajos de la Ponencia, ni en los Anteproyectos. Procede de un complejo proceso de redacción que incluye una 
discrepancia formal pactada y que finalizó con la inclusión del precepto en el trámite del proyecto constitucional en el Senado. Mas vayamos por partes.

El art. 1. GG abre el sistema de derechos fundamentales de la ley fundamental, constituyendo su norma de cabecera. Consagra la dignidad como valor fundamental primario, liga ese reconocimiento con el de los derechos humanos, a los que se califica como inviolables e inalienables, que se definen como fundamento de la comunidad política, y se cierra con un precepto que resulta ser antecedente del art. $53 \mathrm{CE}$. Finalmente el apartado primero del art. 2. establece como el primero de los derechos que especifican la dignidad, como el primero de los derechos humanos, el derecho al libre desarrollo de la personalidad, estableciendo como fronteras del mismo el resto a los derechos de los demás, al orden constitucional y a la ley morali.

Los preceptos iniciales de la GG han sido interpretados por el BVfG de tal modo que el Tribunal atribuye a la dignidad de la persona el estatuto de valor jurídico supremo del orden constitucional, entendiendo que la dignidad es inherente a la condición humana y que, en consecuencia, se debe afirmar a que allí donde hay vida humana hay dignidad, y ello aun en los casos en los que no haya ni conocimiento de la misma ni capacidad para ejercerla².

1 Los textos son los siguientes:

Art.1.

1. La dignidad de la persona humana es intangible. Todos los poderes públicos han de respetarla y protegerla.

2. El pueblo alemán reconoce los derechos humanos, inviolables e inalienables, como el fundamento de toda comunidad humana, de la paz $y$ de la justicia en el mundo.

3. Los derechos fundamentales que a continuación se proclaman vinculan a los poderes legislativo y ejecutivo y a los tribunales de justicia, como derecho inmediatamente aplicable.

Art.2.

1. Todos tienen el derecho al libre desarrollo de su personalidad en la medida en que no atente contra derechos de otras personas y no vulnere el orden constitucional y la ley moral.

El texto de la GG se cita según la edición del CEC vide Gómez Orfanel, G. y López GuerRa, L., Las constituciones de los Estados de la Unión Europea, CEC, Madrid, 1996, págs. 35/6.

2 Vide von Munch, I., "La dignidad del hombre en el Derecho Constitucional», REDC n. ${ }^{\circ}$, Madrid, 1982, págs. 11 y 16. 


\section{HISTORIA DE LA REDACCIÓN}

La redacción del art. 10.CE fue en su día compleja, puesto que en principio ni el precepto antecedente tenía una redacción similar, ni era remotamente parecida la ubicación sistemática en el texto. Las actas de la Ponencia ${ }^{3}$ son sumamente parcas, no indican por regla general la orientación de los debates, ni las posiciones de los ponentes, ni las razones de adopción de un determinado precepto o una determinada redacción. Son además incompletas, no hay actas desde principios de noviembre de 1977 hasta marzo del 78, falta la redacción del Borrador -que fue objeto de filtración-y de la propia del primer anteproyecto, no recoge el debate sobre las enmiendas presentadas a éste y es parco respecto de la producción del segundo Anteproyecto. Pese a sus insuficiencias es una fuente preciosa para el estudio de la elaboración de la Constitución de 1978.

Por lo que al tema afecta el antecedente más remoto del actual 10.1. se halla en el art. 16 aprobado por la Ponencia el seis de septiembre de 1977. En el mismo la influencia del art. $1 \mathrm{GG}$ es aplastante:

\section{Art. 16}

1. Se reconoce la dignidad de la persona humana.

2. Los derechos inviolables de la persona son fundamento del orden político y de la paz social.

3. El reconocimiento, respeto y protección de estos derechos informará la legislación positiva, la práctica judicial y toda la acción de los poderes públicos. 4

La primera redacción del art. 10.1 es poco más que una simplificación del art. 1. GG, cuya estructura se reproduce, del que desaparecen la declaración de intangibilidad de la dignidad - sin duda por entenderla declaración superflua - la definición de los derechos como inalienables y se da una redacción próxima a la definitiva de lo que luego serán el inciso final del art. 53.1. y el art. 53.3.

No obstante la redacción no pareció satisfactoria y en la revisión del día 8 el texto se amplía incorporando un nuevo apartado segundo que recoge la sustancia del art. 2.1. GG y su derecho al libre desarrollo

3 "Actas de la Ponencia Constitucional», en RCG n. ${ }^{\circ} 1$, Madrid, 1985, págs. 251 y ss.

4 Actas, op. cit., pág. 264. 
de la personalidad5, si bien cambia el diseño de las fronteras: el orden constitucional y la ley moral se transmutan en el respeto a la ley, en tanto que se mantiene la cláusula del respeto a los derechos ajenos. De este modo la práctica totalidad de los elementos del actual art. 10.1. se hallan ya presentes. La nueva redacción, aún más "germánica" que la anterior, reza así:

Art. 16

1. Se reconoce la dignidad intangible de la persona humana.

2. Se garantiza el libre desarrollo de la personalidad dentro del respeto a la ley y a los derechos de los demás.

3. Los derechos inviolables de la persona son fundamento del orden político y de la paz social.

4. El reconocimiento, respeto y protección de estos derechos informará la legislación positiva, la práctica judicial y toda la acción de los poderes públicos. 6

Ahora bien, la revisión general del texto que condujo a la elaboración del Borrador afecta de modo importante a nuestro caso: el borrador contiene una redacción distinta. El art. 16 que ahora pasa a ser el ordinal 13, contiene un único apartado en el que se refunden los cuatro de la segunda redacción, del que desaparecen además las cláusulas que van a pasar al hoy art. $53 \mathrm{CE}$. El borrador fija definitivamente el texto del apartado primero del art. 10, que ya no sufrirá alteración textual en todo el proceso constituyente ${ }^{7}$.

Lo que si sufre alteración es su ubicación en el texto. En principio se hallaba tras los referentes a la nacionalidad y mayoría de edad, ubicado entre estos y la declaración de derechos propiamente dicha, y conserva tal posición en las cuatro primeras redacciones del texto. No obstante, en el marco de la reelaboración general que la declaración de derechos sufre por obra de la Ponencia, entre el primer y el segundo anteproyecto, el precepto pasa a ocupar la cabecera del Título primero, ubicación sistemática que ya no se verá alterada ${ }^{8}$. La razón del cambio de ubicación del precepto la manifestará en términos inequívocos uno de los Ponentes, el profesor Peces-Barba, en el debate en la Comisión del Congreso:

5 La inclusión es deliberada, las Actas anotan que se acordó la inclusión de un nuevo apartado referente a la garantía del libre desarrollo de la personalidad. $A c-$ tas..., op. cit., pág. 265.

6 Actas..., op. cit., pág. 267.

7 Actas..., op. cit., pág. 283.

8 Actas..., op. cit., pág. 372. 
Es un artículo que....sirve para señalar el soporte de todo el título I sobre los derechos fundamentales. ${ }^{9}$

El debate del art. 10.1. en la tramitación parlamentaria es magro, y fuera de las rotundas afirmaciones de Peces-Barba en el sentido de que el precepto acoge una concepción personalista y que excluye cualquier concepción totalitaria ("transpersonalista») apenas si se registra observación alguna de interés, fuera del intento socialista de cambiar la expresión "paz social»10. El acuerdo general no genera debates.

Distinto es el iter constitucional del apartado segundo. Carente de cualquier clase de antecedente nacional ${ }^{11}$ el precepto, que supone una cierta internacionalización de la declaración de derechos, tiene su más remoto origen en la temprana propuesta ucedista de dar valor constitucional al CEDH y a la Carta Social Europea12, según una posición cara a uno de los ponentes de UCD, el sr. Herrero de Miñón. Dicha propuesta no tiene continuación inmediata y no reaparece hasta el trámite de enmiendas al primer anteproyecto, en el que se avanzan propuestas en este sentido por el sr. Arias Salgado. Estudiada por la Ponencia, registra un acuerdo de principio y un desacuerdo pactado ${ }^{13}$, la propuesta es replanteada por Canyellas (UDC) en el Congreso ${ }^{14}$, y es

9 Peces-BaRBa, DSCACLP 17/5/78, pág. 2393. Años después escribirá: «Si estipulamos un sentido, podemos entender como fundamento de los derechos aquellas razones morales, que derivan de la dignidad del hombre y que son condiciones sociales de la realización de la misma». Vid. Peces-Barba, G. et alii, Curso de Derechos Fundamentales, Teoría General, Universidad Carlos III/BOE, Madrid, 1995, pág. 209.

10 El texto me parece tan ilustrativo como claro: «Precisamente el fundamento del orden político y social son la dignidad de la persona, los derechos inviolables de la persona humana y el libre desarrollo de la personalidad.Se da a ese orden político y social un contenido que impide una construcción transpersonalista y totalitaria del mismon. PeCEs-BARBA, DSCD 5/7/78, pág. 3888.

11 En cuanto al derecho comparado el único referente, y aun así parcialísimo se halla en la remisión a la Declaración Universal del art. 16.2. de la Constitución portuguesa.

12 Actas..., op. cit., pág. 262.

13 Actas..., op. cit., p.394. merece mencionarse que la citada enmienda no aparece en el BOCE, el texto reza: "Declaración de los grupos Socialista y Comunista de reconsiderar, en su día, su postura y aceptar la enmienda del señor Arias Salgado respecto del Título II que propone la remisión a las declaraciones internacionales", lo que acredita el carácter de espectáculo que revistieron las discusiones sobre el futuro art. 10.2. en ambas Cámaras, y explica la aceptación final del precepto y su inclusión en el texto constitucional.

14 Enmienda 244 al art. 6 del primer anteproyecto, pasa a ser enmienda al art. 89 del segundo anteproyecto BOCE 1/07/78 pág. 2636. El texto era diferente al 
rechazada por verse en la misma una propuesta técnicamente deficiente, aunque la razón de fondo radicaba en contemplarla como un intento de desvirtuar el consenso sobre el actual art. 27.7. CE a la luz de lo que establecen el art. 13.3. y 4 PIDCP $y$, sobre todo, el art. 18.4. PIDESC.

Rechazada por el Congreso no sin afirmaciones a favor de UCD reaparece en el Senado, donde una enmienda ucedista ${ }^{15}$ es aceptada ${ }^{16}$, introduciendo el nuevo apartado, ante la oposición frontal del PSOE, que, de acuerdo con el compromiso manifestado en Ponencia en marzo, acaba aceptando el texto mediante el expediente de una pérdida pactada de votación. El texto, levemente retocado por la Comisión Mixta ${ }^{17}$, deviene así definitivo.

\section{EL DISCURSO DEL ART. 10.1}

La primera cuestión a considerar, con carácter previo, radica en precisar si nos encontramos ante normas constitucionales o mas bien ante un texto encuadrable dentro de la categoría de la retórica constitucional. La cuestión ha sido planteada por fuente que debemos considerar autorizada, uno de los padres de la Constitución, cuya influencia personal es destacable precisamente en la materia de que tratamos: el profesor Peces-Barba. Al efecto el profesor y ponente constitucional ha venido a sostener que el art. 10.1. CE es un texto de emotiva retórica a través del cual se percibe la influencia del iusnaturalismo pero que, a la postre, constituye un cuerpo extraño. Al respecto escribe:

definitivo art. 10.2 y se limitaba a establecer la superior jerarquía de los convenios internacionales que desarrollaban la Declaración Universal. El debate en DSCACLP, 6/6/78, págs. 2949 y ss. El debate en el Pleno, en DSCD, 13/7/78, págs. 4223 y ss.

15 Enmienda 707 de UCD, su tenor era el siguiente:

2. Las libertades y derechos serán tutelados y garantizados de conformidad con los acuerdos internacionales sobre derechos humanos ratificados por España.

16 DSS. Comisión Constitucional $23 / 8 / 78$ págs. 1738 y ss. la enmienda ucedista fue modificada en el curso del debate, incorporando en buena medida una propuesta del grupo PSI vid. pág. 1755, cuyo texto era ya muy similar al definitivo, a su vez el mismo es modificado mediante una enmienda in voce que deja el texto poco menos que en sus términos finales, vid. pág. 1758. Votación, p. 1761. El debate en el Pleno, DSS, 26/9/78, págs. 2952 y ss. Votación, pág. 2954. En ambas votaciones UCD votó a favor y los socialistas se abstuvieron.

17 La Comisión suprimió el término "demás» que figuraba antes de la palabra "tratados". 
"En el tema de los derechos es fàcil incurrir en el error de usar tèrminos emotivos que susciten sentimientos $y$ que no sean autènticamente relevantes para expresar mandatos, permisos o prohibiciones si se trata de normas primarias, o para organizar poderes, establecer competencias o fijar procedimientos si se trata de normas secundarias. El titulo primero contiene un precepto de esa naturaleza impregnado de retórica iusnaturalista, que es el art. 10.1:.. Son palabras vàlidas, quizàs, para el preàmbulo, pero que no añaden nada al carácter normativo de la Constituciòn."

Y agrega a renglón seguido:

"Incluso pueden crear confusiòn al contrapesar el sentido muy claro del art. 1.1 donde se señalan los valores superiores, fundamento de los derechos humanos y de la organizaciòn de los poderes, como expresiòn de la dignidad de la persona humana, cuya promociòn es finalidad del poder politico. Es un fundamentalismo sin mayor alcance..." 18

Dejando de lado los matices de antipatía doctrinal, el profesor Peces-Barba viene a criticar el enunciado constitucional en cuestión por tres razones distintas: supone un inciso iusnaturalista, carece de contenido normativo y es susceptible de entrar en colisión con el enunciado del art. 1.1. CE. La primera objeción sólo puede ser entendida como rechazo de una posición doctrinal que se predica del enunciado constitucional. Aunque el debate pueda ser interesante en términos de Filosofía del Derecho, la crítica es completamente inane desde la perspectiva del Derecho Constitucional. Que un precepto constitucional obedezca a una determinada posición doctrinal o a una determinada orientación ideológica en nada empece a su naturaleza jurídica, y en nada impide que sea considerado parte de la Constitución. Que el apartado primero del art. $10 \mathrm{CE}$ obedezca a, o venga a recoger, una orientación iusnaturalista no es clase de argumento alguno esgrimible frente a su valor normativo. Si el precepto contiene normas tendrá contenido normativo, en caso contrario no, en el primer supuesto tales normas podrán tener mayor o menor grado de afinidad con las posiciones personales, pero ello nada agrega, y nada resta, al citado valor normativo. La primera es, pues, una crítica estrictamente ideológica,

18 Peces-Barba Martinez, G.: Derecho y Derechos Fundamentales, CEC, Madrid, 1993, pág. 193. 
que tiene exactamente el mismo alcance e identidad que la que podría hacerse desde una posición opuesta, esto es ninguno. A lo sumo podría decirse que el apartado primero del art. 10 está redactado en términos tales que presupone que los derechos constitucionalmente reconocidos de algún modo son anteriores a dicho reconocimiento por parte del Poder Público, y que éste seria de algún modo debido, pero, con independencia de que la misma o muy similar observación puede hacerse de numerosos enunciados de la declaración de derechos, mediante los cuales "se reconocen" derechos, resultando obvio que sólo puede reconocerse lo previamente de algún modo existente, tales afirmaciones si bien se corresponden con el iusnaturalismo - bien sea este tradicional o racionalista - también es cierto que son predicables de posiciones que bien poco en común tienen con las citadas. A la postre el "iusnaturalismo" criticado queda en si mismo en muy poco más que en la asunción por parte de la Constitución española de los «derechos humanos" y resulta a mi juicio bastante claro que estos devienen incomprensibles si no satisfacen dos condiciones: corresponder a los seres humanos qua humanos, y no depender exclusivamente de su positivización a la hora de desplegar eficacia, aun jurídica. No me parece, por otra parte, que sea inscribible en el reino de la casualidad que el autor de referencia sea bien conocido por su reticencia al uso en el terminologìa jurídica de la denominaciòn "derechos humanos" y su preferencia por la que entiende como alternativa de "derechos fundamentales". Ahora bien, si el precepto constitucional asume la noción de los «derechos humanos" (como ha afirmado el TC, según veremos más adelante), la constitucionalización de dicho concepto y, en su caso, de las consecuencias jurídicas que puedan seguirse de esa incorporación comportará que el constituyente ha positivado una concepción que es incompatible con la posición doctrinal sostenida por el profesor citado, pero esa divergencia en nada afecta a la normatividad constitucional, aunque ciertamente si ello es así hay que extraer la consecuencia pertinente, debida desde la perspectiva de la supremacía constitucional: la mentada reconstrucción doctrinal es radicalmente inhábil al efecto de interpretar al menos esta parte de la Constitución.

Mayor entidad tiene la segunda objeción. Desde luego resulta obvio que el enunciado del art. 10.1.CE no contiene normas primarias, en el sentido de que no contiene normas que por si mismas manden, permitan o prohiban nada. Otra cuestión es si dicho enunciado contiene normas secundarias, en el sentido de normas que establecen organización o instituciones, delimitan o atribuyen competencias o asignen fines o establezcan procedimientos para el ejercicio de estas. Desde esta segunda perspectiva la cuestión nos remite a qué estatuto debamos 
reconocer a los principios. Si se entiende que el ordenamiento está integrado por normas, y solo por normas $y$ que, en consecuencia, los principios - entendidos como no-normativos - se hallan fuera de aquel habría que convenir en que al profesor y ponente no le falta razón, pero si estima, por el contrario, que el ordenamiento esta integrado por normas y principios, de tal modo que estos últimos viene a organizar la producción, modificación o extinción de las primeras $y$, amén de ello, los principios fijan y organizan la estructura en la que aquellas se insertan la objeción deviene inadmisible. El art. 10.1 contiene principios, precisamente aquellos que estructuran la declaración de derechos y permiten hablar, en nuestro caso, de un verdadero sistema de derechos constitucionales - fundamentales o no - y no de un mero agregado de derechos y de enunciados sobre derechos carentes de articulación. Es más, incluso desde una perspectiva estrictamente pragmática para la cual " Derecho es una buena profecía acerca de lo que decidirá un Juez" como gustaba decir Holmes, no cabe duda de que los enunciados del art. 10.1 CE son Derecho, como más adelante se verá.

La tercera de las objeciones, la colisión con los valores superiores del art. 1.1 CE, me parece incomprensible. Si, como señala el profesor correctamente, aquellos valores son expresión de la dignidad humana, y esta fundamenta la República, resulta ser que eso es, exactamente, el contenido primario y principal del art. 10.1 de tal modo que lejos de haber colisión ambos preceptos constitucionales se refuerzan mutuamente, por lo que malamente puede haber entre ambos conflicto alguno. La objeción, no obstante, me parece reveladora de la posición del profesor Peces-Barba, ya que, como es bien sabido, el autor ve en el art. 1.1 CE la consagración de su posición doctrinal "dualista" sobre los derechos fundamentales, en tanto que esa misma posición doctrinal tropieza con serias dificultades a la hora de cohonestarla con el enunciado del art. 10.1 CE, siendo, a mi juicio, es el único alcance real de la crítica que comentamos. Despejada la posible duda acerca de la naturaleza jurídica y valor normativo del apartado primero del art. 10 CE es hora de entrar en su consideración.

Por lo que toca al discurso del art. 10.1 CE el punto de partida resulta ser el mismo que en la GG: la dignidad de la persona, a ella se anudan los derechos, que el texto define como inviolables e inherentes, los derechos actúan con cláusula de unión entre la dignidad y el libre desarrollo de la personalidad, configurándose la doble frontera del respeto a la ley y a los derechos de los demás como una frontera común a la autodeterminación personal y a los derechos inherentes, el 
enunciado se cierra con la determinación del estatuto del sistema de derechos fundamentales sus principios y fronteras: ser fundamento el orden político y la paz social. El bloque normativo queda constituído, pues:

Primero. Por dos enunciados principiales: dignidad y libre desarrollo de la personalidad de tal modo que la ordenación léxica implica la primacía lógica del primero sobre el segundo.

Segundo. Por la configuración de un sistema de derechos fundamentales y sus fronteras que especifican aquellos principios ${ }^{19}$. Siendo dichas fronteras son, además, indicador de la prioridad lógica del principio de dignidad sobre el de autonomía.

Tercero. Por la configuración del conjunto anterior (principios, sistema de derechos y fronteras de estos) como base y fundamento de la ordenación constitucional del Estado (el orden político) y la misma sociedad civil (la paz social) ${ }^{20}$.

Tal vez merezca la pena destacar aquí que el texto constitucional es portador, en este punto cuanto menos, de una concepción universalista de los derechos humanos, como lo es necesariamente una concepción de tales derechos que ve en la dignidad la fuente de los mismos. Los derechos fundamentales de la Constitución española de 1978 son derechos del hombre, y sólo excepcionalmente lo son del ciudadano. Tienen por ello una muy fuerte pretensión de validez que les confiere una posición peculiar en el ordenamiento constitucional, cosa que por demás formaliza el art. $168 \mathrm{CE}$. Esa concepción universalista es la que se halla en el transfondo de la copiosa jurisprudencia constitucional orientada a asimilar en la titularidad y condiciones de ejercicio de los derechos constitucionales tanto a nacionales como a extranjeros que viene a fundamentar, aunque de modo imperfecto, el art. $13 \mathrm{CE}$. Empero no está de más precisar que sólo la positivización de los derechos humanos en la forma de derechos fundamentales introduce claramente a los primeros en el ordenamiento $y$ hace que sean derechos

19 Entiendo por principio a los efectos que siguen aquella norma que establece mandatos de orientación $y$ organización de las reglas, de tal modo que permiten una aplicación graduada en función de las circunstancias, tanto jurídicas como materiales. Ello comporta que no me parece completamente satisfactoria la definición que efectúa Alexy del principio como mero mandato de optimización. Vid. ALEXY, R.: Teoría de los derechos fundamentales, CEC, Madrid, 1993, págs. 86 y ss.

20 Hay que señalar que, aunque formulada en términos bien distintos, el concepto de la dignidad como fundamento del orden político se halla en el art. 1 de la Constitución portuguesa. 
en el estricto sentido juridico del término, como advierte, por ejemplo, Torres del Moral21.

Aunque según un tópico muy extendido el art. 10.1 supone un inciso iusnaturalista de inspiración netamente democristiana, esta última me parece una opinión en exceso aventurada. Como ha señalado con justeza Solozábal el precepto es susceptible de una interpretación en clave kantiana. Es más, a mi juicio la estructura subyacente al enunciado del precepto que comentamos es plenamente congruente con el modelo kantiano: la racionalidad/ dignidad fundamenta la autonomía individual y permite al hombre vivir según sus propias máximas, pero esas máximas sólo pueden conceptuarse leyes y escapar del subjetivismo siendo tenidas por morales si satisfacen la regla de la universalidad que concretizan las fronteras de la autonomía personal misma ${ }^{22}$. La similitud estructural salta a la vista. No en vano la dignidad es un valor central en la teoría kantiana del Derecho, al tiempo que también lo es del sistema de derechos constitucionales que la ley fundamental de 1978 establece, es más, como veremos más adelante con algún detalle, es probable que aunque similarmente inexacta la observación opuesta tuviere mayor corrección: el apartado primero del art. $10 \mathrm{CE}$ es, a no dudarlo, un muy calificado aspirante al título de precepto más kantiano de la Constitución vigente. Mas todo se andará.

\section{LA DIGNIDAD DE LA PERSONA}

El sujeto del enunciado constitucional viene descrito como la "persona" $y$ es de la misma de quien se predica la "dignidad». El enun-

21 Vid. Torres del Moral, A.: Principios de Derecho Constitucional Español (4. a ed. abrev.), Servicio de Publicaciones de la Facultad de Derecho, UCM, Madrid, 1998, pág. 253.

22 Ad exemplum: "La libertad del arbitrio es la independencia de su determinación por impulsos sensibles; este es el concepto negativo de la misma. El positivo es: la facultad de la razón pura de ser por sí misma práctica. Ahora bien, esto no es posible más que sometiendo la máxima de cada acción a las condiciones de aptitud para convertirse en ley universal. En efecto, como razón pura, aplicada al arbitrio sin tener en cuenta el objeto de éste, como facultad de los principios (y aquí de los principios prácticos, por tanto, como capacidad legisladora) no puede - ya que la materia de la ley le abandona- sino convertir la forma misma de la aptitud de la máxima del arbitrio para convertirse en ley universal en ley suprema y fundamento de determinación de arbitrio, y prescribir esta sólo como imperativo de la prohibición o de mandato, dado que las máximas del hombre que proceden de causas subjetivas no coinciden por sí mismas con las objetivas". (KANT, I.: La metafísica de las costumbres, Tecnos, Madrid, 1989, 214, pág. 17). 
ciado plantea dos problemas: en primer lugar que debe entenderse por "persona" en el sentido del art. 10.1. CE; en segundo lugar que hay que entender por "dignidad" en dicho enunciado. Corresponde, pues, afrontar ambos problemas, por demás estrechamente relacionados entre sí, en primer lugar cual es el concepto de "persona» en el enunciado constitucional, $y$, ligado a la gama de respuestas posibles a dicha cuestión, aproximarse al problema de cual sea el concepto de "dignidad" que el enunciado constitucional contempla. No obstante no está de más señalar una importante diferencia entre el texto constitucional español y su prototipo alemán: a diferencia de lo que ha venido a entender el Tribunal Constitucional germano sobre la base del art. 1. GG, en nuestro caso la dignidad no es un derecho fundamental, entre otras razones porque no es un derecho ${ }^{23}$. Precisamente porque es "pórtico" de la Declaración de Derechos, y se integra en la norma de cabecera de la misma en nuestro caso la dignidad es un principio organizador $y$ vertebrador del sistema de derechos fundamentales, pero no es, en si misma considerada, objeto específico de un particular derecho fundamental ${ }^{24}$. Lo mismo cabe decir del «libre desarrollo de la personalidad", que es considerado asimismo en el caso alemán como un derecho fundamental, configurado como un derecho general de libertad (si bien en este caso con apoyo textual en el art. 1.3. GG) cuyo papel en el sistema de derechos fundamentales alemán se ha revelado disfuncional y que, en razón de ello, ha sufrido una fuerte crítica doctrinal25. De ello se sigue que cual sea el significado y alcance del concepto de persona en el art. 10.1. CE es problema distinto y que por sì mismo no prejuzga la solución al problema de la titularidad de derechos fundamentales ${ }^{26}$.

Empero cabe plantearse si sería posible una interpretación del art. 10.1. que configurara dignidad $y$ libertad como derechos fundamentales de carácter general, al estilo alemán. A mi juicio la respuesta

23 Ese es precisamente uno de los argumentos fundamentales de la decisión del TC en el caso de la Ley de Técnicas de reproducción asistida STC 116/99 FJ 4.

24 Lo que hace impracticable la extensión a nuestro sistema de derechos de la concepción de la dignidad simultáneamente como principio y como regla que hace Alexy para el caso germano vid. AleXY, R.: Teoría..., op. cit., págs. 106 y s.

25 Vid. Alexy, R.: Teoría..., op. cit., págs. 331 y s., con abundante bibliografía.

26 Aquí radica mi punto fundamental de divergencia con la tesis sostenida por Morote Sarrión. Vide Morote Sarión, J.: El concepto de persona en el ordenamiento jurídico español. Una aproximación. Tesis doctoral inédita. Valencia, 1999, passim. 
a dicho interrogante debe ser negativa ${ }^{27}$. Por de pronto lo abona la interpretación literal, ya que el enunciado constitucional no registra tal definición; asimismo lo abona la interpretación sistemática del precepto, pues si el enunciado del mismo hace derivar los derechos fundamentales de la dignidad y de la libertad, de tal modo que dichos valores son la fuente de tales derechos mal pueden, a su vez, ser derechos fundamentales; a renglón seguido refuerza esta interpretación la ubicación del precepto, que encabeza el título primero, pero no está encuadrado en ninguno de los capítulos que la ley fundamental dedica a la regulación de los derechos constitucionales, tanto si se trata de derechos fundamentales como si no; en cuarto lugar refuerza la conclusión mencionada el apartado primero del art. 53, que viene a excluir a dignidad y libertad de la condición de derechos con fuerza vinculante, $y$, además, los sitúa fuera de la enérgica reserva de ley $y$ de la consiguiente cláusula de contenido esencial, lo que no tendría el menor sentido si se tratara de derechos; finalmente opera en el mismo sentido el apartado segundo del art. 53, que excluye dignidad y libertad general del ámbito del recurso de amparo, cosa que resultaría sencillamente incomprensible si se tratare de derechos fundamentales, y lo sería aún más si se tratare de derechos fundamentales que operan en el sistema como fuente de todos los demás ${ }^{28}$.

Rechazada, pues, por incompatible con los enunciados constitucionales, la posibilidad de configurar como derechos a la dignidad y la libertad no parece haber obstáculo alguno para ver en ellos lo que, a mi juicio, efectivamente son en nuestro sistema de derechos constitucionales: los principios del mismo. En cuanto tales principios dignidad

27 Posición similar sostienen de Esteban y González-Trevijano. Vid. de Esteban, J. y González-Trevijano, P. J.: Curso de Derecho Constitucional Español. 2 v., Servicio de Publicaciones de la Facultad de Derecho, UCM, Madrid, 1993, v. II, pág. 25 y s.

28 El voto particular de Jiménez de Parga a la STC 116/99 plantea un problema interesante: sentado que el Tribunal ha venido admitiendo una concepcion material de la ley orgánica, según la cual las materias conexas a aquella que exige regulación mediante tal instrumento legal resulta exigible que aquellas regulaciones que afecten directa e inmediatamente a la dignidad de la persona (el argumento es válido asimismo para la libertad personal) revistan la forma de ley orgánica:

Mas aún: cuando la dignidad de la persona se configura, por expresa declaración constitucional, con derechos inviolables inherentes a ella, no resulta aceptable, en mi opinión, que la ley orgánica sea necesaria para desarrollar los derechos fundamentales y no para desarrollar lo que, materialmente es el tronco del gran árbol. Dar un tratamiento constitucional distinto al tronco y a las ramas no es propio de la visión no exclusivamente formal de la reserva que este Tribunal ha consagrado. VP FJ 2 in fine. Ciertamente la cuestión merece una consideración más detenida que la que le dedican los FJ 3 y 4 de la STC 116/99. 
y libertad cumplen en el sistema una cuádruple función: en primer lugar operan como preceptos - fuente de los enunciados constitucionales que reconocen derechos (de todos los derechos, y no solo de los estrictanente fundamentales); en segundo lugar permiten establecer una ordenación coherente de dichos enunciados $y$, mediante ellos, de los derechos que la Constitución reconoce; en tercer lugar vienen a constituir instrumentos de uso necesario al doble efecto de interpretar dichos enunciados y resolver, en su caso, los supuestos de concurso de derechos constitucionales; finalmente vienen a definir como un conjunto coherente una parte sustancial tanto del orden vinculante de convivencia constitucionalmente prescrito como del modelo de Estado que la Constitución viene a imponer.

\section{a) El problema de la upersona»}

Como reza una afirmación ya convertida en tópica la palabra "persona" tiene un origen grecorromano. En griego y latín clásico el término antecedente nace significando máscara teatral $y$, por extensión, papel o personaje en una obra de teatro. Como señala Cotta ${ }^{29}$, el cristianismo introduce progresivamente un cambio, persona se desliza de designar un conjunto de roles a significar ser humano, el derecho romano postclásico ya utiliza esa acepción persona es igual a ser humano. En el latín medieval se mantiene esa identificación, que será de uso común por la escolástica.

A partir del Renacimiento se va a producir una separación creciente entre los conceptos de hombre y persona. Este adquiere progresivamente el significado de sujeto dotado de capacidad jurídica, en consecuencia se convierten progresivamente en moneda corriente dos afirmaciones estrechamente interrelacionadas: de un lado no todos los seres humanos son personas, pues no todos tienen esa capacidad, del otro se atribuye la condición de persona a entes que no son seres humanos, dando lugar a las personas jurídicas.

La acentuación de la separación ser humano/capacidad jurídica lleva al extremo de deshumanizar completamente el concepto de per-

29 Cotta, S.: Persona (filosofía del diritto) en Enciclopedia del Diritto, Giuffré ed., Milan, 1983, t. XXXIII, págs. 159 y ss. Escribe el autor: "Una análoga e imitativa aventura tiene el término latino de persona: máscara primero, como se ha dicho, parte y personaje teatral después, a la postre hombre, como registra sin dificultad Gaion (pág. 161). 
sona, reducido a centro de imputación de derechos, deberes y obligaciones. Ese es el punto en el que se inserta la concepción civilista de la persona que consagran los arts. 29 y ss. del CC.

No parece que el concepto civil de persona sea aplicable al caso que tratamos. En tanto en cuanto éste excluye a una parte de los nacidos y extiende el concepto a personas jurídicas, que no puede ser titulares de algunos de los derechos fundamentales que se deducen por la Constitución misma del concepto de "dignidad de la persona», dicha interpretación resulta recusable.

En el polo opuesto se hallaría la interpretación que consiste en identificar persona y ser humano tout court, que sostiene, por ejemplo, Martinez-Pujalte ${ }^{30}$. Ciertamente esa identidad persona/ ser humano es la que mejor conviene a aquellas concepciones de la dignidad que marcan el acento en la sustantividad humana, pero se compadece mal, o no se compadece en absoluto, con todas aquellas que de alguna manera ven en la racionalidad y en la consiguiente capacidad moral el eje de la dignidad misma. Dignidad y persona en el art. 10.1 se tornar así conceptos interdependientes.

Ahora bien, si consideramos la cuestión en términos de capacidad de derechos fundamentales, ninguna de esas dos posturas extremas a venido a ser aceptada por la jurisprudencia del TC, esta ha venido a entender "persona" como equivalente de ser humano nacido (cf. STC 53/85 y 212/96) ${ }^{31}$. Tal posición es, a su vez, criticable, por operar una desconexión casi completa entre personalidad y dignidad, y no só-

30 Vid. Martínez-Pujalte, A. L.: Hacia un concepto constitucional de persona, CCCFFC, n. ${ }^{\circ} 11 / 12$, Valencia, 1996, pág. 141 y ss. Trabajo que conviene en sostener que la determinación de que sea persona en el sentido del art. 10.1. CE prejuzga por sí sola la cuestión de la titularidad de derechos fundamentales.

31 Mientras que en la primera (FJ 5) se identifica persona con ser humano nacido sin otra referencia sólida que la posición de la Comisión Europea de Derechos Humanos, en la segunda el Tribunal da por cerrada la cuestión:

Aplicado a un embrión o feto humano, su caracterización como "no viable» hace referencia concretamente a su incapacidad para desarrollarse hasta dar lugar a un ser humano, a una "persona» en el fundamental sentido del art. 10.1. CE. STC 212/96 FJ 5.

Doctrina reproducida en la STC 116/99, FJ 9, en la que, coherentemente, se rechaza directamente que los gametos o preembriones no implantados sean «persona humana" FJ 11. No entro ahora a considerar la sustantividad y adecuación del concepto de "preembrión" que me parece cuanto menos dudosa, lo que me lleva a considerar cuanto menos discutible la doctrina constitucional que otorga distinto grado de protección jurídica al embrión según esté implantado o no, doctrina que es común a las dos Sentencias antecitadas. 
lo por ofrecer espacios a la legitimación legal del aborto, aun parcial, razón última de la mayor parte de las críticas.

Si tomamos como punto de partida la posición del TC, persona vendría a ser el ser humano cuya existencia está anidada en sociedad por el hecho del nacimiento y que, como consecuencia, puede ser un sujeto jurídico y, como tal, titular de derechos, deberes y obligaciones. El nacimiento da certeza a la existencia y viabilidad y confiere el grado mínimo de alteridad que es exigible para integrarse en la red de relaciones sociales y con ello, para ser titular de bienes y derechos. En este sentido cabría alegar incluso el art. $29 \mathrm{CC}$, que no en vano recurre a la configuración de una fictio iuris para proteger al no nacido.

Formulada en tales términos, en cuanto solución al problema de la titularidad de derechos fundamentales, la posición del TC no es susceptible de seria polémica. La divergencia que se halla en la raíz de la mayor parte de las criticas que a la misma se dirigen tiene que ver mas con el fallo del Tribunal en la STC 53/85 que con una argumentación razonable no ya en torno al apartado primero del art. 10 de la Constitución, sino sobre el problema concreto de la titularidad de determinados derechos subjetivos. Dicha divergencia radica en el estatuto que se atribuye al no nacido en las diversas fase de su evolución (huevo, embrión, feto) y para ello en la afirmación o negación de su carácter de persona, con las repercusiones sobre la definición de dicho concepto que son de rigor.

La cuestión del concepto de persona en el sentido del art. 10.1. CE no debe ocultar, sin embargo, que aun si aceptamos en sus propios términos la acepción de persona que asume como indicada el TC la vida intrauterina, en cuanto fase previa necesaria a la vida extrauterina, se beneficia necesariamente de la protección que la Constitución de a la segunda al ser la primera su presupuesto. En consecuencia la dignidad que se predica del ser humano nacido no puede sino predicarse al menos parcial y limitadamente del no nacido. La cuestión se desplaza, pues, a determinar si es posible configurar la dignidad de modo paralelo a la vida humana, esto es como un proceso y no como un estado.

En todo caso me parece más razonable entender que cuando el art. 10.1. usa el concepto de persona no sólo no usa el mismo en ninguna de las acepciones técnicas, sino que, siguiendo un uso habitual en la redacción de las normas constitucionales, usa aquel en el sentido que recibe en lenguaje común, vulgar, de tal modo que persona en el sentido del art. 10.1, CE vendría usado en su acepción no técnico-jurídica en cuyo caso por "persona" habría que entender lo que señala el 
DRAE esto es "individuo de la especie humana» 32 aunque, desde luego, ello implica la imposibilidad de proyectar directa e inmediatamente ese concepto vulgar sobre la cuestión, distinta, aunque próxima, de la titularidad de derechos fundamentales. Persona en el sentido del art. 10.1. CE vendría a identificarse con "ser humano" y ello en cualquiera de las situaciones en las que un individuo de nuestra especie pueda encontrarse. Es de la persona en este sentido entendida del que la Constitución predica la nota de dignidad, con lo que no hace sino seguir el camino que en su día abrió el preámbulo de la Declaración Universal33.

Retomando el hilo me parece que la indagación puede afrontar el problema que tratamos según el orden léxico del precepto, en cuyo caso la investigación debería partir del concepto de dignidad, y entender el concepto que designa su titular a partir de aquel. Y ello por la buena razón de que ese es el camino que el texto mismo nos señala.

\section{b) La dignidad}

El término dignidad es asimismo de origen latino, y en la Roma republicana designa la posición social y rango que en la República pueden alcanzar los cives. En este sentido la dignitas es la especial valoración que se da de un ciudadano en función de su rango social, posición política y actuación. La dignitas romana es, pues, un concepto aristocrático, sólo los que tienen una posición en la República poseen en ella un rango y por ello tienen dignitas y la poseen en cuanto mantienen o acrecientan aquella posición.

El cristianismo operará una radical democratización de la dignitas que alterará sustancialmente su concepto. El cristianismo introduce la idea de esencial igualdad de todos los seres humanos y con ella la consecuente de que el valor y rango de los mismos es esencialmente el mismo. Mas esa democratización va asociada al surgimiento de la idea según la cual todos los seres humanos son intrínsecamente valio-

32 El Diccionario de uso acepta la misma definición y la consagra como acepción promera y cuidadosamente reserva la significación tecnico-jurídica (quinta acepción) a la concepción de la misma como mero centro de imputación de derechos y deberes. Vid. Seco et alii, Diccionario del Español actual, 2 v., Aguilar, Madrid,1 999. 2 v., V. II, págs. 3498/9.

33 No me resisto a señalar aquí que es ésta, a mi juicio, la razón primaria que hace adecuada y dota de fundamento sólido a la tesis central de la STC 53/85: que el feto, en cuanto vida humana aun no nacida, es un bien constitucionalmente protegido por el art. $15 \mathrm{CE}$. 
sos por serlo, fundamentándose ese valor propio en que todos los seres humanos, en cuanto creados por Dios, lo han sido a imagen y semejanza del mismo. En el discurso cristiano, $y$ en el humanista que de él se sigue, el hombre es intrínsecamente igual a los demás hombres y es, además, es un ser valioso en sí, cualitativamente distinto de las cosas y del mundo de la naturaleza, porque ese valor propio que deriva de su condición de imago Dei.

Si el hombre es imago Dei se sigue que el ser humano posee un valor absoluto en su condición de tal, en tanto en cuanto ser humano, valor que exige por si mismo el respeto incondicionado que en la dignidad ven, por ejemplo, Benda ${ }^{34}$ o Álvarez Conde 35 .

La dignidad aparece así como la fusión de dos ideas genéticamente ligadas: la sustantividad ontológica del ser humano y el valor propio, inherente a la condición humana misma, que de cada ser humano se predica, del cual es consecuencia el derecho a "igual consideración y respeto" del que habla Dworkin. Valor propio que se afirma como contrapuesto al valor relativo o relacional que es propio de la naturaleza y de las cosas, valor propio del que los derechos del hombre son consecuencia y especificación. El concepto de dignidad se encarna en estos términos en la tradición del humanismo cristiano y en el iusnaturalismo, para los cuales la dignidad es un concepto central.

La dignidad tiene asimismo un papel central y recibe una interpretación sólo parcialmente distinta desde la óptica alternativa más importante que se ha elevado frente a la tradición cultural mencionada, una óptica kantiana. Como heredero del iusnaturalismo Kant afirma como rasgo distintivo de humanidad la dignidad, es esta la que marca la distancia entre la valoración de las cosas y la de los hombres ${ }^{36}$, que consiste sustancialmente en que el hombre es un fin en sí mismo ${ }^{37}, \mathrm{cu}$ yo fundamento es la capacidad moral del hombre definida por la racionalidad y la imputabilidad ${ }^{38}$.

34 BENDA, E.: "Dignidad humana y derechos de la personalidad", en BENDA ET ALII, Manual de Derecho Constitucional, M. Pons, Madrid, 1996, págs. 117 y 120.

35 Álvarez Conde, E.: El régimen político español, 3.a ed., Tecnos, Madrid, 1987, pág. 120. Hay edición posterior.

36 KANT, I.: Fundamentación de la metafísica de las costumbres, Espasa-Calpe, Madrid, 1983, pág. 82.

37 KANT, I.: Fundamentación..., op. cit., pág. 93; en el mismo sentido, vid. del mismo autor La metafísica..., op. cit., pág. 335.

38 Kant, I.: La metafísica..., op. cit., pág. 30. 
Como señala Münch ${ }^{39}$, ninguna de las tradiciones puede reclamar para si la tarea de definir el único fundamento del concepto constitucional. No obstante el concepto de la tradición cultural y el kantiano coinciden en tres afirmaciones nucleares:

Primera, la dignidad se concibe como la cualidad del ser humano de ser valioso por sí mismo ${ }^{40}$.

Segunda, ese valor propio sitúa al hombre en un rango superior a la naturaleza, las cosas y las relaciones sociales y exige en el seno de estas últimas un reconocimiento y respeto incondicional. Los derechos fundamentales son su consecuencia41.

Tercera, la dignidad es inseparable de la vida humana, en cuanto propiedad de ésta nace con la misma y sigue necesariamente su suerte, en tanto en cuanto el hombre es racional y libre, o en la naturaleza racional como gusta señalar Maihofer.

En contrapartida los dos conceptos divergen en al menos otras tres: el distinto ámbito que reconocen a la autonomía personal, en el tipo de normas éticas a las que subordinan a la persona (sustanciales o procesales), en la fundamentación de la dignidad misma.

En todo caso la coincidencia de las dos tradiciones que conforman la mainstream del concepto resulta llamativa en un punto crucial: ambas sitúan la dignidad como una característica de la naturaleza humana. En consecuencia ambas coinciden en atribuir la dignidad al ser humano qua humano, y, por tanto, a atribuirle dignidad desde el instante de su aparición en el mundo hasta el de su extinción. De ello me parece se siguen cuanto menos cuatro afirmaciones cargadas de con-

39 MüNCH, I.: La dignidad..., op. cit., págs. 12/13.

40 Puede proponerse, y se ha propuesto, una concepción de la dignidad que venga a asimilar ésta con la autodeterminación personal, como, por ejemplo, hace Nino, vid. Nino, C. S., Ética y Derechos Humanos, Ariel, Barcelona, 1989, pág. 287 y ss., bien directamente, bien en términos de pretensión de respeto de la autonomía personal. Pero, a nuestros efectos, hay que señalar que una concepción de este tipo es incongruente como el enunciado constitucional, que diferencia claramente dignidad y autonomía, $y$ hace derivar la segunda de la primera. Amén de entrañar una desconexión esencial entre persona y dignidad, pues resulta obvio que si la autonomía define la dignidad los seres humanos carentes de la primera carecerán asimismo de la segunda, lo que implica que hay seres humanos dignos y otros que no lo son, lo que no parecen tampoco compatible con el enunciado constitucional.

41 Lo que implica que la dignidad no es un derecho humano específico, sino la fundamentación de los mismos, como señala SPAEMANN, R., Sobre el concepto de dignidad humana, PyD, n. ${ }^{\circ}$ 19, Pamplona, 1988, pág. 15. 
secuencias por lo que a las cuestiones relacionadas con los derechos fundamentales y su régimen jurídico-constitucional respecta:

Primera, si la dignidad es un atributo humano la misma se predica del hombre desde su origen, esto es, desde la concepción, los diversos estadios evolutivos previos al nacimiento son claves para su desarrollo y perfeccionamiento como tal, pero el dato esencial de ser valioso por sí mismo, y no per relationem le acompaña desde el ini$\mathrm{cio}^{42}$

Segunda, si ello es así parece que la respuesta más ajustada al enunciado constitucional del principio de dignidad es aquella que identifica persona con ser humano, sujeto al que se aplica el predicado de que tratamos.

Tercera, que aun cuando es cuestión distinta - bien que nada distante - la de la medida en que el ser humano no nacido es, sentada su dignidad, titular de la capacidad de derechos fundamentales, la gama de soluciones al problema de dicha titularidad compatibles con el enunciado constitucional se ve drásticamente reducida.

Cuarta, la dignidad, en cuanto atributo humano, resulta indisponible, con las consecuencias que son de rigor. Por ende cabe afirmar que su misma naturaleza confiere a la dignidad la condición de estado, y no de proceso, como lo es la vida humana. En consecuencia no cabe gradación de la dignidad 43 .

Todo parece apuntar, pues, que de las dos gamas de acepciones que se puede anudar al concepto de persona, la que la entiende como sujeto de Derecho y la que la contempla como ser humano, la segunda es más adecuada a la hora de dotar de sentido al inciso inicial del art. $10 \mathrm{CE}^{44}$, como ya se señaló.

42 Ese es el criterio que según von Munch sigue el BVfG. Vid. von Münch, I., La dignidad..., op. cit., pág. 16. Asimismo ese es el criterio que sigue la reciente Declaración de las Naciones Unidas sobre el genoma humano, que adopta como punto de partida el principio de dignidad y lo aplica explícitamente al no nacido. Vid. art. 1.

43 Aunque con distinta argumentación tal es la tesis que en este punto sostiene Alegre Martínez. Vid. Alegre Martínez, M. A., La dignidad de la persona como fundamento del ordenamiento constitucional español, Universidad de León, León, 1996, pág. 49.

44 Es de señalar que la ambivalencia alcanza incluso a la autoridad lingüística. Así el Diccionario manual de la RAE la recoge a la hora de definir el término persona. Vid. RAE, Diccionario manual e ilustrado de la lengua española, Espasa-

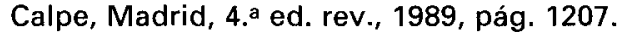


En consecuencia, si predicamos la dignidad del ser humano dado que la mera condición humana no atribuye eo ipso, de modo inmediato, la condición de sujeto de Derecho (y con ella la capacidad de derechos fundamentales) en los ordenamientos modernos, de lo cual son buena prueba los enunciados de los arts. 29 y s. CC, habrá que considerar que la dignidad propia del hombre, si bien no fundamenta por sì sola la personalidad jurídica, si fundamenta un derecho fundamentalísimo a la misma, significativamente esa es la conclusión a la que llega el Tribunal Constitucional germano a partir de los enunciados de los arts. 1.1.(dignidad) y 2.1 (libertad) de la GG. En todo caso, y por lo que a nuestro caso afecta si la regla hermenéutica del art. 10.2. CE es predicable del art. 10.1. CE, es de interés señalar que esa es la conclusión a la que es preciso llegar a la vista de lo que dispone el art. 6 de la Declaración Universal, cuyo texto francés reza:

Chacun a droit à la reconnaissance en tous lieux de sa personnalité juridique. ${ }^{45}$

En todo caso debe retenerse que el enunciado en cuestión es en España derecho vigente, al ser reproducido literalmente en el art. 16 PIDCP, del cual es parte nuestro país ${ }^{46}$.

Lógicamente la realización de dicho derecho, esto es el reconocimiento por el ordenamiento de la personalidad jurídica, puede ser gradual en función de la certeza del sujeto y su capacidad efectiva, material, de ejercicio de los derechos. La condición humana del feto fundamenta así la aplicación a la misma de la protección que a la vida humana dispensa el art. 15. CE, y lo hace de modo juridicamente más

45 Se cita por la edición del Consejo de Europa. Vid. CONSEIL DE L'Europe: Les droits de l'homme en droit international, Strasbourg, 1991, págs. 3 y 25.

46 No me parece que esté de más señalar que, aunque el enunciado del art. 6 DUDH y el concordante del art. 16 PIDCP se hallan dirigidos a combatir la esclavitud, y no a afrontar y resolver el problema de la titularidad de derechos públicos subjetivos de naturaleza constitucional, de un lado vienen a abonar la tesis expuesta del sentido vulgar del empleo del concepto "persona"tanto en dichos documentos internacionales como en el art. 10.1. CE (en este caso interpretación reforzada por la norma hermenéutica del art. 10.2. CE), y del otro a prejuzgar una solución de la cuestiòn de la titularidad de derechos fundamentales sumamente favorable cuanto menos a la máxima extensión retroactiva posible de la personalidad juridica en el caso del feto, es decir viene a amparar una interpretación "dura" de la máxima nasciturus pro iam nato habetur que imperfectamente recoge el $\mathrm{CC}$. Desde la cual no resulta completamente satisfatorio más de un aspecto de la doctrina sentada en Ja STC 53/85. 
sólido y argumentativamente más convincente que la gratuita, por inmotivada, afirmación de la STC 53/85 según la cual el feto es un bien constitucionalmente protegido.

Cuestión distinta es la de si el principio de dignidad es, en nuestro caso, un principio de carácter absoluto o no. La ubicación sistemática y la posición que el principio ocupa en la economía del precepto constitucional parecen indicar una solución afirmativa, como por demás se ha planteado respecto de las normas-modelo de la GG que, como hemos visto, se hallan en el trasfondo del art. 10.1 CE. Naturalmente la cuestión no radica en la centralidad del principio de dignidad, que resulta evidente por sí misma en el marco de nuestro sistema de derechos, sino mas bien en la cuestión dogmática de si son posibles principios absolutos, tesis esta última que no parece sostenible, pues un principio que revistiera tal carácter sería siempre y necesariamente prevalente en caso de conflicto. No obstante la cuestión no puede reducirse a la constatación de que siendo susceptible de juicios de prelación no cabe predicar carácter absoluto, porque ese planteamiento es, en sí mismo, equívoco, además de sumamente peligroso para la integridad de los derechos constitucionales e incongruente con la existencia en nuestro ordenamiento de la cláusula de contenido esencial. Una cosa es que la dignidad comporte una exigencia de respeto incondicionado hacia cada ser humano y otra bien distinta que las consecuencias de ese respeto puedan entrar en concurso con las exigencias de la protección de otros bienes constitucionalmente protegidos $y$, en consecuencia, nos hallemos ante la necesidad de ordenación de normas de principio aplicables al caso.

A mi juicio la cuestión debe plantearse de otro modo, la dignidad del art. 10.1 CE es un concepto jurídico indeterminado que se emplea por el constituyente para fundamentar el entero sistema de derechos ${ }^{47}$, de tal modo que todos y cada uno de los derechos constitucionales, sean estos fundamentales o no, no son sino concretizaciones de dicho principio, o de su correlato necesario el principio de libertad. En tanto que concepto jurídico indeterminado le es aplicable la distinción entre el núcleo y las penumbras, de tal modo que si bien el núcleo mismo si puede reclamar una primacía absoluta e incondicionada frente a otros bienes y valores constitucionalmente protegidos dicha reclamación no es siempre y necesariamente predicable de las penumbras, en las cuales hay campo para recurrir, en caso necesario a la ponderación de bie-

$47 \quad Y$ cada derecho en particular.Vide ad exem. STC 224/99 FJ 2 y 3. 
nes en conflicto. De otro lado hay que señalar que la dignidad es ponderable, en cuanto a sus penumbras, pero no frente a derechos constitucionales concretos, que mal pueden fundamentar reclamaciones ante el principio que su propio fundamento, sino frente a otros bienes constitucionalmente protegidos, pues solo entre bienes es factible la ponderación ${ }^{48}$.

El sistema de derechos fundamentales que la Constitución establece se nos ofrece así bajo un perfil harto tradicional, pues prácticamente desde su mismo nacimiento las Declaraciones de Derechos han venido a tomar como punto de partida la dignidad. Me parece que en este punto es acertada la opinión de Perez-Luño ${ }^{49}, y$ tal apreciación viene corroborada por la lectura, aun superficial, de los documento internacionales en la materia: tanto la Declaración Universal, como el Pacto Internacional de Derechos Civiles y Políticos, como el de Derechos Económicos, Sociales y Culturales invocan la dignidad como pieza maestra de las declaraciones correspondientes, situando a aquella como fundamento nuclear de los derechos que reconocen y proclaman. En razón de ello existe una profunda coherencia interna entre el enunciado principial del art. 10.1 y la cláusula hermenéutica del art. 10.2 CE.

Por último no está precisar aquí que un sistema de derechos constitucionales que sitúa en la raiz de estos el principio de dignidad $y$, en consecuencia, los deduce de éste y de su correlato necesario, el principio de libertad, es un sistema de derechos constitucionales que prejuzga desde su fuente un determinado tipo de solución a la cuestión de la titularidad de derechos por extranjeros. Pues, en efecto, si los derechos derivan del principio de dignidad y esta se predica de todo ser humano, se sigue necesariamente que en línea de principio los extranjeros no pueden ser excluídos de la titularidad de los derechos, al menos de aquellos derechos de los que podamos predicar una relación de inmediación con aquel principio. El régimen de asimilación entre el extranjero y el nacional que anuncia el art. 13 CE y al que ha dado una interpretación expansiva el Tribunal Constitucional, tiene

48 Pues los principios tienen, como se señaló, carácter normativo, y las normas se ordenan, pero no se ponderan. Lo que a mi juicio es un error -estimar que puedan ponderarse los principios, en el que, por cierto, incurre Alexy por apegarse demasiado a la jurisprudencia- obedece al hecho de no tener suficientemente en cuenta que en tanto que normas los principios protegen bienes, y que la distinta importancia de estos en el caso puede tener peso decisivo en la ordenación de las normas aplicables.

49 Vid. Pérez-Luño et alii: Teoría del Derecho. Una concepción de la experiencia jurídica, Tecnos, Madrid, 1997, pág. 223 y ss. y 232 y s. 
aquí su base. Es más, si alguna observación merece el régimen del art. 13 CE sería mas bien que su enunciado no es suficientemente flexible. La experiencia ha justificado esa observación: fue necesario modificar el art. 13 CE para poder ratificar el tratado de la Unión Europea ya que éste, al introducir la ciudadanía de la Unión, atribuía derechos políticos a los extranjeros reșidentes que fueren ciudadanos de la Unión misma.

\section{c) La dignidad de la persona en la jurisprudencia del TC}

Por lo que toca al sujeto de la dignidad la doctrina del Tribunal es, como ya se ha señalado, al tiempo parca y confusa, parca por razón de su extrema escasez, ya que son un puñado las Sentencias del Alto Tribunal en las que de algún modo éste entra a considerar la cuestión, y aun asi prácticamente siempre lo hace a título de cuestión secundaria, cuando no periférica de la cuestión que aquel debe resolver. Como ya se ha señalado el Tribunal viene a entender que sólo las personas tienen capacidad de derechos fundamentales, entendiendo por tales a los seres humanos nacidos, si bien a la postre el Tribunal Constitucional no aporta otro argumento en favor de su tesis que la escasamente convincente invocación de la doctrina de la Comisión Europea de Derechos Humanos ${ }^{50}$. De hecho el Tribunal da un paso más y aplica la tesis elaborada para afrontar la cuestión de si el feto es titular de derechos fundamentales, en especial vida e integridad física y moral para aplicarla a la interpretación del art. 10.1. CE, lo que no parece una decisión especialmente afortunada.

En contrapartida el Tribunal sí parece inclinarse por entender persona en el sentido de ser humano a la hora de determinar quien es titular ordinario de derechos fundamentales ${ }^{51}$, y a especificar que las

50 Escasamente convincente desde el momento en que la citada Comisión era, hasta su reciente extinción, un órgano esencialmente intergubernamental, "político" en la acepción corriente y errónea del término, y no es un órgano jurisdiccional. No obstante lo cual no es infrecuente que el TC invoque su autoridad para fundamentar sus decisiones. Vid. ad exem. STC 114/84 FJ 3, 133/88 FJ 3, 57/94 FJ 6 o 29/95 FJ 5.

51 Ad exem.: "Es indiscutible que, en línea de principio, los derechos fundamentales y las libertades públicas son derechos individuales que tienen al individuo como sujeto activo $y$ al estado como sujeto pasivo en la medida en que tienden a reconocer y proteger ámbitos de libertades o prestaciones que los Poderes Públicos deben otorgar o facilitar a aquellos. Se deduce así sin especial dificultad, del art. $10 \mathrm{CE}$, que, en su apartado 1, vincula los derechos inviolables con la digni- 
personas no humanas —es decir, las jurídicas- sólo son titulares de tales derechos por extensión ${ }^{52}$.

Distinta es la conducta seguida por el Tribunal en orden a establecer su interpretación de la dignidad del art. 10.1. CE. Desde luego el TC elude consciente y deliberadamente la formulación de un concepto de dignidad, del mismo modo que evita cuidadosamente una determinación exhaustiva de su contenido material. $Y$ hace bien, definir no es función propia de un órgano jurisdiccional. Ello no excluye, sin embargo, que el TC si efectúe aproximaciones al concepto y precise algunas de sus consecuencias. Para lo que aquí interesa baste decir:

Primero. Que, a juicio del Tribunal, la dignidad es un valor jurídico fundamental, es inherente a la persona, y que el mismo es un valor que se manifiesta en la autodeterminación personal ${ }^{53}$. En tanto en cuanto atributo de humanidad postula derechos iguales ${ }^{54}$, es precisamente el menoscabo de la dignidad que producen lo que induce al constituyente a calificar como discriminatorias determinadas causas de diversidad de trato.

dad de la persona y con el desarrollo de la personalidad y, en su apartado 2, los concreta con los llamados derechos humanos...". STC 64/88 FJ 1.

52 Ad exem.: "Es cierto, no obstante, que la plena efectividad de los derechos fundamentales exige reconocer que la titularidad de los mismos no corresponde sólo a los individuos aisladamente considerados, sino también en cuanto se encuentran insertos en grupos y organizaciones, cuya finalidad sea específicamente la de defender determinado ámbitos de libertad o realizar los intereses y los valores que forman el sustrato último del derecho fundamental". STC 64/88 FJ 1.

53 Ad exem.: "Junto al valor de la vida humana y sustancialmente relacionado con la dimensión moral de ésta, nuestra Constitución ha elevado también a valor jurídico fundamental la dignidad de la persona, que, sin perjuicio de los derechos que le son inherentes se halla íntimamente vinculada con el libre desarrollo de la personalidad (art. 10) y los derechos a la integridad física y moral (art. 15), a la libertad de ideas y creencias (art. 16), al honor, a la intimidad personal y a la propia imagen (art. 18.1.). Del sentido de estos preceptos puede deducirse que la dignidad es un valor espiritual y moral inherente a la persona, que se manifiesta singularmente en la autodeterminación consciente y responsable de la propia vida y que lleva consigo la pretensión al respeto por parte de los demás". STC 53/85 FJ 8.

54 Ad exem.: "..., pues existen derechos que corresponden por igual a españoles y extranjeros y cuya regulación ha de ser igual para ambos" (STC 107/84 FJ 4); así sucede con aquellos derechos fundamentales "que pertenecen a la persona en cuanto tal y no como ciudadano", o, dicho de otro modo, con "aquellos que son imprescindibles para la garantía de la dignidad humana que conforme al art. 10.1. de nuestra Constitución constituye fundamento del orden político español". STC 99/85 FJ 2. 
Segundo. La dignidad es un bien constitucionalmente protegido y dicho bien lo es de tal modo que vincula a todos, y no sólo a los poderes públicos ${ }^{55}$.

Tercero. La dignidad es, en unión de la vida un presupuesto del sistema de derechos fundamentales ${ }^{56}$. Además, y precisamente por ello,la dignidad define un mínimo esencial que todo estatuto jurídico debe respetar so pena de incurrir en inconstitucionalidad ${ }^{57}$.

Cuarto. La dignidad excluye la reducción a objeto o instrumento de la persona humana ${ }^{58} y$, en consecuencia, excluye la patrimonialización del propio cuerpo, y, por tanto, la posibilidad de convertirle en fuente de rendimiento económico59.

55 Ad exem.: "Pues bien, hemos de afirmar que ni la libertad de pensamiento ni el derecho de reunión y manifestación comprenden la posibilidad de ejercer sobre terceros violencia moral de alcance intimidatorio, porque ello es contrario a bienes constitucionalmente protegidos, como la dignidad de la persona y su derecho a la integridad moral (art. 10 y $15 \mathrm{CE}$ ), que han de respetar no sólo los poderes públicos, sino también los ciudadanos, de acuerdo con los artículos 9 y 10 de la norma fundamental". STC 2/82 FJ 5.

56 Ad exem.: "Indisolublemente relacionado con el derecho a la vida en su dimensión humana se encuentra el valor jurídico fundamental de la dignidad de la persona, reconocido en el art. 10 como germen o núcleo de unos derechos «que le son inherentes". La relevancia y significación superior de uno y otro valor y de los derechos que los encarnan se manifiesta.en su colocación... o que muestra que dentro del sistema constitucional son considerados como el punto de arranque, como el prius lógico y ontológico para la existencia y especificación de los demás derechos». STC 53/85 FJ 3.

57 Ad exem.: "Ello, sin perjuicio de que la regla del art. 10.1.CE, proyectada sobre los derechos individuales, implica que la dignidad de la persona ha de permanecer inalterada cualquiera que sea la situación en la que la persona se encuentre, constituyendo, en consecuencia, un mínimum invulnerable que todo estatuto jurídico debe asegurar, de modo que las limitaciones que se imponen en el disfrute de derechos individuales no conlleven menosprecio para la estima que, en cuanto ser humano, merece la persona, aunque sólo en la medida en que tales derechos sean tutelables en amparo y únicamente con el fin de comprobar si se han respetado las exigencias que, no en abstracto, sino en el concreto ámbito de cada uno de aquellos, deriven de la dignidad de la persona. habrá de ser tomada en cuenta por este Tribunal como referente" (STC 120/90 F.J. 4) STC 57/94 FJ 3 A).

58 Ad exem.: "La dignidad de la mujer excluye que pueda considerársela como mero instrumento, $y$ el consentimiento necesario para asumir cualquier compromiso y obligación cobra especial relieve en este caso ante un hecho de tanta trascendencia como el de dar vida a un nuevo ser, vida que afectará profundamente a la suya en todos los sentidos". (STC 53/85 FJ 11 b).

59 Ad exem.: "Tal reproche carece totalmente de sustento desde el momento en que esta singular "donación" al igual que la de órganos humanos regulada en la ley $30 / 79$, o incluso la del cadáver de una persona, no implica en modo 
Amén de alguna otra propiedad colateral, como actuar de soporte del principio de proporcionalidad de la pena ${ }^{60}$.

\section{LOS DERECHOS: INHERENCIA E INVIOLABILIDAD}

En el discurso del art. 10.1. CE el principio de dignidad viene a operar como fundamento de los derechos individuales, la secuencia del texto mismo es inequívoca en el sentido de ligar dignidad y derechos de tal forma que esta es el presupuesto y causa de los segundos $^{61}$. En principio habría que considerar que, a partir de la primera aproximación que el análisis gramatical proporciona, la cláusula se estructura en torno a tres afirmaciones: en primer lugar los derechos individuales proceden de la dignidad humana; en segundo lugar que tales derechos van unidos necesariamente a la condición humana; en tercer lugar que un ordenamiento como el constitucional que reconoce dichos derechos no puede haber conducta lícita contradictoria con los mismos. $Y$, aunque no sea este el punto en que corresponde tratar la cuestión, no debe olvidarse que tales derechos son parte esencial del Estado Constitucional, y por tanto del Estado Constitucional Democrático 62 .

\section{a) Los derechos inherentes e inviolables}

En rigor el contenido normativo del segundo inciso del art. 10.1. CE va bastante más allá, y sus implicaciones son tan importante cuanto numerosas. Simplificando me parece que dicho contenido puede resumirse del siguiente modo:

Primero. El precepto al señalar que los derechos fundamentales son "inherentes" está postulando la existencia de un orden jurídico prepositivo anterior a la Constitución misma, orden jurídico que asien-

alguno la "patrimonialización", que se pretende, de la persona, lo que sería desde luego incompatible con su dignidad (art. 10.1 CE), sino, justamente, la exclusión de cualquier causa lucrativa o remuneratorian. STC 212/96 FJ 8.

60 Vid. STC 65/86 FJ 2 y 150/91 FJ 4.

61 Incluso un autor crítico con el precepto como Peces-Barba, a la postre viene a coincidir en la tesis primaria de aquel: "Tampoco tiene sentido hablar del concepto de un derecho, al que no se puede encontrar una raiz ética vinculada a las dimensiones centrales de la dignidad humana" (PeCEs-Barba, G. et alii: Curso..., op. cit., pág. 104).

62 Vid. STC 34/86 FJ 1. 
ta en el valor dignidad, en sí mismo anterior al ordenamiento63. En consecuencia los derechos fundamentales no son creados por la voluntad del constituyente, y no provienen por ello del principio mayoritario, en rigor ni siquiera puede sostenerse que sean cogenerativos con el principio democrático, al estilo de lo que sostiene Habermas siguiendo una interpretación "liberal" del Contrato rousseauniano64. La inviolabilidad no es sino una consecuencia o especificación de la inherencia, y una propiedad que deriva de la pertenencia de los derechos fundamentales a ese ordenamiento suprapositivo. Formulada la misma idea en otros términos podrían escribirse así: si hay derechos del hombre, si la expresión "derechos humanos" tiene una significación jurídica precisa, estos son necesariamente derechos prepositivos que el Estado reconoce y positiva en forma de derechos fundamentales. La «inherencia e inviolabilidad" nos remiten al iusnaturalismo y a la tradición liberal e ilustrada que viene de Locke, aunque no exige necesariamente un posicionamiento iusnaturalista en el sentido tradicional de la expresión, exige, eso sí, la consideración de la existencia de unos derechos no le-

63 La observación según la cual el reconocimiento de derechos inviolables remite a un ordenamiento prepositivo es un tópico en la doctrina germana. $A d$ exem., vid. von MüNCH, I., op. cit., pág. 26, o BENDA, E., op. cit., pág. 118. Lo mismo cabe decir del "deber de reconocimiento" que sigue. Cabe señalar que, a la postre, no es infrecuente que quienes niegan esa idea y postulan que los derechos en su estadio prepositivo son poco más que pretensiones dotadas de una especial racionalidad frecuentemente acaban por admitir indirectamente su naturaleza de Derecho al admitir la legitimidad del recurso a derechos no positivizados para decidir casos difíciles. Como ejemplo vid. Peces-Barba, G. et alii: Curso..., op. cit., pág. 105.

64 Ad exem.: "Ni el ámbito de la autonomía política de los ciudadanos viene restringido por derechos naturales o morales que, a fuer de tales, solo estuviesen esperando a que se les diese forma positiva, ni tampoco la autonomía privada del individuo queda simplemente instrumentalizada para los fines de una legislación soberana. A la práctica de la autodeterminación de los ciudadanos no le viene dado previamente nada si no es el principio de discurso, el cual viene inscrito en las propias condiciones de la "sociación" comunicativa, por un lado, y el medio que representa el derecho, por otro. Al medio que es el derecho hay que recurrir si el principio de discurso ha de implementarse en el procedimiento de producción de normas como principio de democracia o principio democrático con ayuda de iguales derechos de comunicación y participación. Ciertamente el establecimiento del código jurídico como tal representa ya derechos de libertad que generan el status de personas jurídicas y garantizan la integridad de estas. Pero estos derechos son condiciones necesarias que no hacen más que posibilitar el ejercicio de la autonomía política; y como condiciones posibilitantes, no pueden restringir la soberanía del legislador, aun cuando no estén a disposición de éste, es decir, aun cuando éste no puede disponer de ellos a voluntad. Las condiciones posibilitantes no imponen restricciones a aquello que constituyen". Habermas, J., Facticidad y validez, Trotta, Madrid, 1998, págs. 193/4. 
gislados, de los cuales los legislados son una consecuencia o especificación ${ }^{65}$. Derechos no legislados cuya fuente es la exigencia de respeto incondicionado que es consustancial a la dignidad. En consecuencia cualquier propuesta de reconstrucción doctrinal aplicada al sistema de derechos fundamentales debe ser compatible con el mencionado postulado, debiendo entenderse ilícito, en cuanto que contrario a la supremacía constitucional, el recurso a tales efectos de las reconstrucciones doctrinales que no sean compatibles con aquel66.

Segundo. De la prioridad de los derechos fundamentales se sigue que el Estado es portador de un deber de reconocimiento, que se traduce en un deber de positivación de los derechos en cuestión de un lado, y en una limitación de la esfera de acción legítima del Estado, de

65 Un buen ejemplo es la construcción de Dworkin, según la cual el individuo es titular de unos derechos morales que la Constitución convierte en derechos juridicos mediante su reconocimiento. Vid. DworkIN, R., Los Derechos en serio, Ariel, Barcelona, 1984, págs. 276 y ss. La tesis que se sostiene es, en sustancia, similar a la sostenida por Pérez-Luño cuando apunta que alguna clase de iusnaturalismo es indispensable para que tenga sentido la cuestión del fundamento de los derechos humanos. Vid. Pérez-Luño, A. E., Derechos humanos, Estado de Derecho y Constitución, 4. ${ }^{a}$ ed., Tecnos, Madrid, 1991, pág. 136/7.

66 Puede intentarse una reconstrucción basada en el "principio de discurson que dé razón de la peculiaridad señalada de los derechos humanos. Vid. ad exem. Cortina, A., "La ética discursiva", en Camps, V. et alii, Historia de la Ética, Crítica, Barcelona, 1989 e v. V.III, págs. 568 y ss. Otra cosa es que que la ucomunidad ideal de habla" constituya por si sola base suficiente para una teoría coherente de los derechos humanos. Así, por ejemplo la reconstrucción señalada exige que sólo puedan ser titulares de tales derechos quienes posean competencia/capacidad comunicativa, y excluye, en consecuencia, a quienes adolecen de la misma.Por eso nuestra autora se ve forzada a extender la pertenencia a aquella a aquellos de quienes se predica competencia/capacidad virtual, pero la inclusión de quienes tal vez podrían pero aquí y ahora no pueden ser miembros de la comunidad en cuestión no puede basarse en la pertenencia a ésta. Se requiere, pues, una hipótesis accesoria y su exigencia supone una fundamentación cuanto menos adicional y distinta que dificilmente puede ser procedimental. Por lo demás no oculto que una ética, y una concepción de los derechos humanos, estrictamente procesales me parece pertenecen al mismo mundo que los unicornios o los centauros, pues a la postre el procedimiento mismo requiere de fundamentación y esta no puede no ser sustantiva. En consecuencia afirmar, como hace Peces-Barba, que la ética de los derechos humanos tiene un sentido únicamente procedimental, no me parece acertado. Vid. Peces-Barba et alii. Curso..., op. cit., pág. 392. o págs. 403 y s. Es más, una concepción estrictamente procesal sería dudosamente compatible con una concepción como la del profesor y ponente constitucional, que hace de los valores superiores la pieza clave del sistema de derechos,y con razón, ya que estos no pueden no ser materiales. Con razón el citado profesor acaba sosteniendo que los derechos fundamentales se asientan en una moralidad común, fuera de la cual carecen de sustantividad juridica. Vid. Curso..., op. cit., págs. 590/91. 
la otra. Deber de reconocimiento que hace del mismo una conditio sine que non de la legitimidad del Estado mismo, y mediante él de su ordenamiento jurídico, y que comporta una limitación de la competencia propia del Estado, que deja de este modo de poseer esa precondición del poder absoluto que es la competencia universal. Específicamente esta la función primaria que cumple en la economía del precepto la referencia a la inviolabilidad. No en vano señaló en día Peces-Barba que el art. 10.1 es el único residuo iusnaturalista de la Declaración de Derechos. Al deber de reconocimiento le sigue un deber de protección, estrechamente ligado a la inviolabilidad como veremos.

Tercero. La inherencia comporta que puesto que los derechos individuales son especificación de la dignidad y esta es atributo del ser humano, los derechos que son su consecuencia también lo son ${ }^{67}$. El hombre es titular de los derechos individuales por que es tal hombre, de tal modo que ni es posible ser titular de tales derechos sin ser hombre ni es posible ser ser humano sin ostentar al menos el principio de la capacidad de serlo68. Pero si esto es así, y resulta difícil atribuir a la "inherencia» un sentido que no incluya las afirmaciones anteriores, se sigue que el hombre no puede ser privado de los derechos individuales de ningún modo, siendo indiferente al efecto que la voluntad que eleva la pretensión de privación de tales derechos sea heterónoma o autónoma, y, en consecuencia, que no existe poder de disposición sobre los derechos individuales, inviolables precisamente por ello, que devendrían de este modo necesarios ${ }^{69}$.

67 Vid. RuIZ-JIMÉnEZ, J., "Comentario al art. 10», en Alzaga et alii, Comentarios a las leyes políticas. Constitución española de 1978, V. II, Edersa, Madrid, 1984, pág. 115 y s. Aunque con un punto de partida distinto también Rawls viene a sostener que sus «libertades básicas" se deducen del concepto de persona propio de su construcción. Vid. Rawls, J., El liberalismo político, Crítica, Barcelona, 1996, pág. $329 / 30$.

68 En rigor lógico habría que escribir " sin ostentar la titularidad», bien entendido que ello supone decir que el art. 10.1. CE de alguna manera postula el retorno a la concepción medieval persona = ser humano, en contra de la tendencia de los sistemas jurídicos modernos, o bien que postula una recuperación de aquella identidad exigiendo la remodelación de la dogmática jurídica correspondiente.

69 Cuestión distinta es la de si el catálogo de derechos fundamentales agota los mismos, o bien la clàusula fundamentadora que comentamos puede justificar la incorporación de nuevos derechos fundamentales en base a la "vocaciòn de plenitud" de aquella. Vid. ad exem. BaLAGUer CALLEJón et alii, Derecho Constitucional, V. II, Tecnos, Madrid, 1999, pág. 46. Obviamente se trata de derechos fundamentales de declaración judicial introducidos por el TC. A mi juicio la observación es acertada, pero si, y sólo si, es posible anudar y/o deducir un nuevo derecho de las cláusulas constitucionales que fijan los derechos fundamentales. Lo que vá más allá, a 
Cuarto. Lo que nos lleva derechamente al problema del ámbito ${ }^{70}$. En la doctrina se han dibujado al respecto dos posturas: o bien los derechos de referencia son todos los comprendidos como fundamentales en la declaración de derechos, o bien sólo cubre especificamente aquellos derechos de dicho catálogo que pueden entenderse como consecuencia necesaria y directa del principio de dignidad. La división de opiniones en rigor me parece que se basa en un malentendido, al que no es ajena una jurisprudencia constitucional que ha forzado una interpretación extensiva de la titularidad de la mayor parte de los derechos fundamentales en función precisamente de su grado de relación con la dignidad de la persona ${ }^{71}$. A mi juicio el entero sistema de derechos constitucionales, y todos y cada uno de los derechos que la Constitución reconoce, tienen su raíz en el principio de dignidad, en consecuencia proceden del mismo todos los derechos, sean fundamentales o meramente constitucionales, sean derechos de mera autonomía o de prestación, sea cual sea la eficacia jurídica que de los mismos predique el art. $53 \mathrm{CE}$. Donde la ley no distingue no debe hacerlo el operador jurídico. Otra cosa es el grado de inmediación de cada derecho constitucional respecto de la dignidad que es su fuente, y de la particular configuración que el mismo posea, según sea derecho ejercitable plenamente por uno mismo, requiera para su ejercicio el concurso de otro $u$ otros o tenga por presupuesto o no la vida en sociedad.

Quinto. Finalmente la inherencia e inviolabilidad de los derechos que arrastra, como hemos visto, la ausencia de poder de disposición sobre los mismos conlleva una determinada solución al problema de la renunciabilidad de los derechos fundamentales. Esta es clara y simple: si los derechos son inherentes, y en la medida en que lo son, resultan indisponibles ${ }^{72}$. En consecuencia, y al margen de otros moti-

mi juicio, entra de lleno en la competencia del titular del poder de revisiòn. Por demás ejemplos no faltan en la jurisprudencia constitucional, en unos casos con acierto (así sucede con la deducción de un derecho fundamental a los datos que el TC anuda a la vaga garantía del apartado 4 del art. $18 \mathrm{CE}$ ) y en otro sin él (como sucede en el caso de la transmutación del art. 27.10 de lo que obviamente es, una garantía institucional, en lo que no es, un derecho fundamental).

70 Para una discusión del problema en cuestión vid. Alegre Martínez, M. A., La dignidad..., op. cit., págs. 44 y ss.

71 Un resumen de dicha doctrina en Martínez Sospedra, M., Libertades Públicas, 2 v. V. I, F.U. S. Pablo-CEU, Valencia, 1993, págs. 215 y ss.

72 En la doctrina alemana es predominante la tesis según la cual aunque los derechos fundamentales son irrenunciables algunas facultades a ellos pertenecientes si podrían ser objeto de renuncia. Entre nosotros esa parece ser la posición 
vos coincidentes que más adelante se verán, los derechos fundamentales no son susceptibles de renuncia. Cuando la configuración de un derecho fundamental lo permita el mismo podrá no ser ejercido -como sucede paradigmáticamente con aquellos derechos que son de titularidad individual pero de ejercicio colectivo, como ocurre con el de reunión-, pero la titularidad del derecho nunca es disponible, y por ende el mismo no es renunciable. Entiéndase bien, la imposibilidad de la renuncia no dimana del argumento pragmático de la vulnerabilidad de los derechos en caso de su admisión, ese podrá ser un argumento colateral más o menos procedente, pero no pasará de ahí, la irrenunciabilidad es sencillamente la otra cara de la inherencia tomada en serio. Si afirmamos que los derechos fundamentales son los derechos de la persona humana en cuanto tal aquellos aparecen tan estrechamente ligados a ésta que los derechos son constitutivos de humanidad $y$, por ello, tan susceptibles de renuncia como la propia sombra.

Inherencia e inviolabilidad arrastran ciertas consecuencias que, por lo demás, el propio precepto viene a explicitar, como veremos. Por lo demás si bien el Tribunal Constitucional se ha mostrado en la práctica muy reacio a entrar en grandes construcciones doctrinales, en la cuestión que tratamos esa reticencia se ha visto multiplicada en razón de la fuerte carga ideológica del tema que tratamos, Aun así, aunque con parquedad, el TC no ha tenido más remedio que incorporar en sus argumentaciones algunas de las ideas arriba descritas. Así ha venido a utilizar la cláusula de la inherencia para justificar la necesidad del escrutinio estricto en la interpretación de los derechos fundamentales ${ }^{73}$ precisamente sobre la base de considerar a tales derechos como inherentes a la condición humana, a establecer que los derechos fundamentales son permanentes y no susceptibles de prescripción, aunque puedan serlo los instrumentos procesales mediante

de Álvarez Conde. Vid. Álvarez Conde, E., El régimen..., op. cit., pág. 107. Von MünCH la detalla del siguiente modo: "La opinión dominante actualmente en la bibliografía jurídico-constitucional alemana es la de que no se puede renunciar ciertamente al derecho fundamental en cuanto todo, pero sí a determinadas potestades derivadas de un derecho fundamental, en especial si se trata de renuncia temporalmente acotada». Vid. von MüNCH, I., La dignidad..., op. cit., pág. 27.

73 Ad exem.: "La extensión de los derechos fundamentales a todos los ciudadanos, como derechos inherentes a la propia personalidad, exige que las limitaciones a su ejercicio, basadas en la "relación de sujección especial" en que se encuentren ciertas categorías de personas, sólo sean admisibles en la medida en que resulten estrictamente indispensables para el cumplimiento de la misión o función derivada de aquella situación especial». STC 21/81 FJ 15. 
los cuales se defienden ${ }^{74}$ y a afirmar la indisponibilidad de los derechos constitucionales (cf. STC 11/81 FJ 4, 231/88 FJ 3 o 108/89 FJ 3) ${ }^{75}$, si bien la manifestación más clara y radical de dicho criterio se halla en un voto particular 76 .

Entiendo sin embargo que no puede ser suplida la incapacidad para permitir la lesión de un derecho esencial de la personalidad como es el de la integridad corporal, considerado como irrenunciable y no susceptible de disposición dada su naturaleza.

Aunque éste no pueda ser calificado de oscuro.

\section{b) Limitación del poder del Estado y contenido esencial}

La definición de los derechos constitucionales como inviolables e inherentes conlleva, como se ha señalado ya, una limitación del poder del Estado. Desde el punto de vista de la configuración del orden vinculante de convivencia constitucionalmente prescrito dicha limitación supone otra correlativa que afecta al propio sistema de fuentes del Derecho del Estado Democrático: éste no puede producir derecho válido que entre en contradicción con los derechos constitucionales, cuyo núcleo se le sustrae 77 . Desde la óptica del sistema de gobierno constitucionalmente prescrito, tal limitación comporta la exclusión de las especificaciones directas de la dignidad de la persona de la esfera de acción plenamente entregada al dominio del principio democrático, esto es, el de mayoría, los derechos fundamentales vienen a ser, pues, un haz de institutos jurídicos de vocación contramayoritaria, como señala Alexy:

74 Ad exem:: "Los derechos fundamentales, que establecen una relación jurídica entre cada ciudadano y el Estado desde el reconocimiento de aquellos en la Constitución, son permanentes e imprescriptibles, $y$ por ende también lo es el derecho a no ser discriminados por razón de sexo que tienen las aquí recurrentes. Ello es compatible, sin embargo, con que para reaccionar frente a cada lesión concreta que cada ciudadano entienda haya recibido contra ese o cualquier derecho fundamental, el ordenamiento limite temporalmente la vida de la correspondiente acción...". STC 7/83 FJ 3.

75 La primera es, por cierto, bien rotunda: "Los derechos constitucionales son irrenunciables -proposición juridica que es indiscutible» (loc. cit.).

76 STC 215/94 V.P.

77 Como escribe Rawls: “Por lo pronto, la primacía de la libertad significa que el primer principio de justicia confiere a las libertades básicas _enumeradas en una lista- un estatus especial. Tienen un peso absoluto respecto de las razones de bien público y de los valores perfeccionistas. Vid. Rawls, J., El liberalismo..., op. cit. pág. 331. 
El sentido de los derechos fundamentales consiste justamente en no dejar en manos de la mayoría parlamentaria la decisión sobre determinadas posiciones del individuo, es decir, en delimitar el campo de decisión de aquella,78

para lo cual se configura el sistema de derechos constitucionalmente reconocidos de modo que la validez de las normas que dicha mayoría hace (las leyes votadas por las Cortes Generales, los reglamentos adoptados por el Gobierno, paradigmáticamente) depende de su compatibilidad con dichos derechos. Mas vayamos por partes.

Primero. Los derechos fundamentales entrañan limitación del poder público. Según la formula germana consagrada los derechos fundamentales entrañan preceptos negativos de competencia79. En tanto en cuanto aquellos establecen una esfera de acción reservada a la libre decisión individual y reconocen a su titular la disponibilidad de la misma están prohibiendo la regulación material heterónoma pública y privada, por lo que aquí interesa lo primero- de dicha esfera de acción. Al hacerlo no pueden no limitar la propia del poder soberano, y por ende de su titular, en el Estado Democrático el pueblo. Los derechos fundamentales aparece así como reglas de Derecho objetivo que prohiben al Estado Democrático introducir regulaciones materiales en esferas de acción concretas, que de este modo quedan sustraídas al dominio del principio de mayorías. Tales reglas no entrañan una prohibición absoluta de legislar sobre los derechos fundamentales $^{80}$-aunque puede articularse una declaración de derechos de ese estilo, como prueban las diez primeras enmiendas de la Constitución USA - pero si entrañan, siempre y necesariamente, la sustitución de la normación estatal pública por la propia del titular en cuanto al contenido material de la acción individual. El Parlamento puede legislar sobre derechos constitucionales, pero su competencia se ciñe al establecimiento del régimen de ejercicio de los mismos, no comprende la determinación del ejercicio de cada derecho in concre-

78 AleXY, R., Teoría..., op. cit., pág. 412. Incidentalmente esa naturaleza impide la aplicación pura y simple de las técnicas del art. 3.1. CC a la interpretación de los citados derechos fundamentales, ya que la sustancia de tales criterios interpretativos es precisamente entender el derecho fundamental de conformidad con los criterios mayoritarios.

79 HESSE, K., "Significado de los derechos fundamentales", en BENDA et alii, Manual..., op. cit., pág. 91 v s.

80 Razón por la cual la expresión germana antecitada de los derechos fundamentales como cláusulas negativas de competencia sólo puede usarse por su grafismo y a conciencia de que entraña cierto grado de inexactitud. 
to, decisión esta última que se entrega al dominio de la autonomía de la voluntad como medio para hacer factible que el uso del derecho fundamental pueda ser entendido como instrumento de realización de la libertad personal81.

Segundo. De lo cual se sigue cual es la correcta intelección de la denominada "cláusula de contenido esencial" del art. 53.1. CE.En efecto, ésta no hace sino introducir en forma de un precepto constitucional escrito específico una regla que consagra formalmente la limitación del poder estatal-democrático señalada, delimitando cual es el ámbito de la misma. La limitación no prohíbe al Parlamento producir la legislación de desarrollo y aplicación de los derechos constitucionales, pero no entrega la materia de modo pleno al legislador ${ }^{82}$. Este aparece limitado en cuanto a su esfera de acción legitima: el Parlamento no puede lícitamente producir cualquier legislación de desarrollo y aplicación, sino sólo aquella que sea congruente con el telos de cada derecho fundamental, y sea por ello compatible con las normas de la Declaración.Por ello no es casual que el TC haya elaborado en la cuestión

81 O, dicho de otro modo, la existencia de normaciones materiales en la Constitución, y los derechos fundamentales lo son, supone que bajo la Constitución misma hay contenidos normativos que son sencillamente jurídicamente imposibles, en tanto que hay otros que son juridicamente necesarios.

82 Lo que viene a suponer que el juego entre la cláusula de contenido esencial del art. 53.1. CE y la que se comenta del art. 10.1. CE vienen a llevarnos a la conclusión, poco menos que inevitable, de que la denominada concepción "relativa" de la citada cláusula, que viene a reducir la misma a un formalización en el fondo superflua del principio de proporcionalidad no es coherente con los datos normativos de nuestro ordenamiento.Antes bien, el citado juego de las dos mencionadas cláusulas juega claramente en favor de una concepción sustantiva y no meramente procesal de la citada cláusula, una concepción según la cual siempre habrá un núcleo de acción social indisponible por el legislador democrático en el fondo de cada derecho fundamental. Por lo demás la doctrina del TC sobre los medios de determinación de dicho contenido esencial carecen de sentido fuera del presupuesto de una concepción sustancial, que no absoluta, de dicho contenido esencial. No me resisto a señalar que probablemente por la fuerte carga ideológica de la cuestión, la misma es escenario de contradicciones de no escaso porte. Así Hesse se pronuncia en favor de la concepción relativa de la citada cláusula (HESSE, K., "Significado de los derechos fundamentales", en BENDA et alii, Manual de Derecho Constitucional, IVAP-MP, Madrid, 1996, 67, pág. 110), lo que comporta el vaciamiento de una cláusula constitucional determinada, lo que, a su vez, es incongruente con su teoría de la interpretación constitucional, en especial los principios de concordancia práctica y de fuerza normativa, vid. HESSE, K., Escritos de Derecho Constitucional, CEC, Madrid, 1983, págs. 48 y 50 . En otro orden de cosas sería interesante indagar en que medida una cláusula constitucional como la señalada se corresponde con el núcleo de las libertades básicas que Rawls describe como el "espectro central de aplicaciones" insusceptible de restricción. 
una doctrina ${ }^{83}$ cuyo núcleo fundamental radica precisamente en determinar cuales son los medios técnicos mediante los cuales podemos determinar si la esfera de decisión entregada a la autonomía de la voluntad resulta efectivamente salvaguardada. De otro lado parece que la cláusula en cuestión viene a introducir una matizada concepción absolutista de los derechos constitucionales que protege, pues la misma viene a establecer que al menos una parte del contenido normal de todos y cada uno de los derechos constitucionales que protege, precisamente aquella que define la especificidad del derecho afectado, es radicalmente indisponible $y$, por lo mismo, se impone siempre $y$ necesariamente al operador jurídico viniendo a constituir una barrera infranqueable para el legislador, viene a ser el "limite de los límites» de que habla la doctrina germana ${ }^{84}$.

Tercero. La cláusula que comentamos ha sido entendida por un sector de la doctrina como entrañando una limitación implícita del poder de revisión constitucional. Adelantada en su día por de Vega85, la tesis ha sido retomada por Alegre ${ }^{86}$. En resumidas cuentas la misma viene a señalar que siendo el sistema de derechos fundamentales una parte esencial del orden vinculante de convivencia establecido por la Constitución, el mismo integra aquellos elementos de un texto constitucional concreto que definen su perfil propio, de tal modo que su modificación sustancial o supresión comportarían la destrucción de la Constitución existente y su sustitución por otra distinta. En consecuencia la alteración de tales preceptos y, en especial, el que comentamos comportaría no la reforma de la Constitución de 1978, sino su sustitución por un texto constitucional diferente, en el caso que tratamos diferente de raíz. Tal tesis me parece difícilmente discutible. Es cierto

83 La referencia necesaria es, naturalmente, la STC $11 / 81$ FJ 8 y 10 , no obstante me parece relevante señalar que en el FJ7 se describe la esfera de competencia del legislador democrático en la materia del siguiente modo: "Corresponde, por ello, al legislador ordinario, que es el representante en cada momento histórico de la soberanía popular, confeccionar una regulación de las condiciones de ejercicio del derecho, que serán más restrictivas o abiertas..." (el subrayado es mío).

84 Tan es así que incluso un autor que niega en principio el carácter absoluto de los derechos no puede sino acabar por convenir en la atribución de una cierta validez absoluta a la cláusula del 53.1 CE. Vid. Prieto SANCHIS, L., Estudios sobre derechos fundamentales, Debate, Madrid, 1990, págs. 148 y ss. En el mismo sentido se expresa Stern respecto del art. 19.1 GG. Vid. STERN, K., "El sistema de los derechos fundamentales en la República Federal de Alemanian, RCEC n. 1 , Madrid, 1989, pág. 275.

85 DE VeGA, P., La reforma constitucional, Tecnos, Madrid, 1985, pág. 242

86 Alegre Martínez, M. A., La dignidad..., op. cit., págs. 68 y s. 
que, como señala de Vega ${ }^{87}$, la redacción del art. 168.1. CE es tan deficiente que literalmente el art. 10.1. no se encuentra dentro del ámbito protegido por el procedimiento agravado - en rigor una extraña modalidad de producción legal de una nueva Constitución, como señala de pasada el propio art. 168.2 CE-, pero no es menos cierto que al constituir el fundamento del sistema de derechos del T. I CE se convierte necesariamente en un limite, aunque no formal, de dicho poder de reforma.

Cuarto. La inviolabilidad supone que todo acto que lesione o menoscabe los derechos fundamentales que dimanan de la dignidad personal no puede ser conceptuado como conforme a Derecho y que, en consecuencia, no puede haber derecho subjetivo alguno que ampare tales acciones $u$ omisiones, las mismas merecen siempre la tacha de antijuridicidad. $Y$ es aquí donde se debe insertar el deber de respeto y protección del que ya se hizo mención. Si las acciones y omisiones lesivas de derechos constitucionales son antijurídicas se sigue, de un lado, que el Estado no puede amparar, proteger $y$ fomentar las mismas $y$, del otro, que dimana del art. 10.1.CE un deber de protección efectiva que puede exigir, $y$ frecuentemente exige, la tipificación penal de al menos las infracciones más graves ${ }^{88}$. Es por ello que tiene pleno sentido la definición del Código Penal en términos de "Constitución negativa». El legislador viene obligado por el precepto constitucional que comentamos a establecer una protección penal singularizada de todos $y$ cada uno de los derechos constitucionales, no siendo irrazonable pensar que dicha protección penal exige la tipificación de las conductas lesivas de derechos fundamentales, de tal modo que el propio TC ha llegado a afirmar que dicha protección penal, una vez establecida, se integra en el contenido propio del derecho fundamental afectado ${ }^{89}$.

87 DE VEGA, P., La reforma..., op. cit., pág. 148.

88 En rigor habría que plantearse si al deber de respeto y al de protección -que es mucho más amplio que la procura de la protección penal por cierto- no habría que hablar de un deber de fomento, que en nuestro caso derivaría fundamentalmente del art. 9.3. CE, pero que también encontraría fundamento en el art. 10.1. CE, tal parece ser el criterio del TC cuando escribe: "...que los derechos fundamentales no incluyen solamente derechos subjetivos de defensa de los individuos frente al Estado, y garantías institucionales, sino también deberes positivos por parte de éste (vide al respecto arts. 9.2.,17.4.,18.1.y 4., 20.3. y 27 de la Constitución». STC 53/85 FJ 4.

89 Ad exem.: "Ha de quedar claro que el legislador puede proteger los derechos fundamentales penalmente, $y$ en tal caso no es posible desconocer que la protección penal forma parte del derecho fundamental mismo y que la interpretación de acuerdo con la Constitución de las normas penales relativas a los derechos fundamentales es asunto de la competencia de este Tribunal». STC 73/84 FJ 2. 
Quinto. La inviolabilidad y la inherencia comportan finalmente que los derechos que se siguen del doble principio de dignidad y libertad sólo pueden ser limitados en el supuesto de que se de una colisión entre ellos $o$, dicho de otro modo, que los operadores jurídicos solo pueden plantearse legítimamente la concurrencia de una limitación en el ejercicio de uno de tales derechos cuando dicho ejercicio comporte en el caso conflicto con otro u otros derechos constitucionales, de tal modo que la ponderación sólo es legítima cuando se trate de ponderación de derechos constitucionales (o de los bienes que se protegen mediante derecho constitucional específico), y no lo es en modo alguno si al bien o derecho constitucional correspondiente no es posible oponer otro derecho constitucionalmente reconocido o un bien correspondiente a un derecho constitucionalmente reconocido ${ }^{90}$.

\section{EL LIBRE DESARROLLO DE LA PERSONALIDAD}

Junto a la dignidad, que viene a operar como primer principio, el precepto constitucional sitúa "el libre desarrollo de la personalidad", que constituye el segundo principio vertebrador del sistema de derechos establecido por la ley fundamenta|91. El libre desarrollo de la personalidad presupone ésta y su dignidad, no se trata pues de un principio primario, sino de un principio que, en cuanto que presupone lógicamente al anterior se nos muestra como un derivado de éste, siendo en consecuencia un principio secundario, como por demás sugiere el orden léxico del precepto que analizamos. Que se trate de un principio lógicamente secundario no debe extrapolarse en modo alguno, no se trata de un principio de menor calidad que el anterior, antes bien dignidad y libre desarrollo de la personalidad se implican mutuamente. Es cierto que el segundo "fluye" del primero, como escribe Fernandez Segado ${ }^{92}, \mathrm{o}$ que el segundo "materializa" el primero, como escribe Alegre ${ }^{93}$, pero no es menos cierto que el principio de libertad es hasta tal punto una exigencia del de dignidad que sencillamente éste no es pensable sino en íntima asociación con aquél.

90 La primacía de la libertad implica en la práctica que una libertad básica sólo puede ser limitada o negada por mor de una o más libertades básicas. RAWLs, J., El liberalismo..., op. cit., pág. 332. Merece señalarse que la enumeración rawlsiana de esas libertades básicas contiene las libertades que siguen de la integridad de la persona. Ibidem, pág. 328.

91 Vid. Martínez Sospedra, M., Libertades..., op. cit., V.I, págs. 33 y ss.

92 Fernández Segado, F., La teoría..., op. cit., pág. 201.

93 Alegre Martínez, M. A., La dignidad..., op. cit., págs. 29/30. 
En efecto, si la dignidad se define en los términos que hemos visto y supone el señorío del hombre sobre sí mismo se sigue necesariamente que aquella no es concebible sino en el caso de que se reconozca al ser humano la capacidad y la potestad de disponer de sí mismo, de autodeterminarse ${ }^{94}$, en consecuencia tiene toda la razón Maihofer ${ }^{95}$ cuando señala que cualquier ataque a la autodeterminación y/o a la responsabilidad sobre sí mismo supone necesariamente un ataque a la dignidad de la persona. El sistema de derechos fundamentales, precisamente porque se fundamenta en el principio de dignidad, debe estructurarse de tal modo que diseñe una esfera de acción entregada al pleno dominio de la persona a fin de que esta, autodeterminándose, pueda crecer libremente, pueda tratar de realizarse en la medida de sus posibilidades y capacidades.

Entiéndase bien, ello no significa que sea la propia actuación humana la que determinando el valor de la persona determine su dignidad, si así fuere la dignidad requeriría capacidad de obrar, exigiría ejercicio de la misma y sería variable según la realización de dichas obras. Lo que es tanto como decir que no se trataría de un atributo humano, de un lado, y que no consiste en la cualidad de ser valioso por si mismo, sino mas bien de serlo por las obras, del otro, y con ello necesariamente por su utilidad, con lo cual la dignidad resultaría destruida y el hombre se definiría esencialmente por su función social. La base misma de los "derechos humanos" desaparecería. Lo que significa es que el principio de libertad es un correlato del principio de dignidad, que no puede manifestarse ni ser operativo en el supuesto de que el primero faltare. La dignidad postula la libertad, y esta última solo es inteligible dando por supuesta la primera, pues, de otro modo la libertad carecería de un sujeto sustantivo que pudiera ser su titular. No pertenece precisamente al reino de la casualidad que aquellas concepciones políticas que niegan o desconocen el principio de dignidad tengan una suerte de afinidad electiva con una concepción funcional - subordinada por tanto- de los derechos individuales. La observación vertida por

94 No en vano escribe Kant: "La libertad (la independencia con respecto al arbitrio constrictivo de otro), en la medida en que puede coexistir con la libertad de cualquier otro según una ley universal, es éste derecho único, originario, que corresponde a todo hombre en virtud de su humanidad - La igualdad innata, es decir, la independencia que consiste en no ser obligado por otros sino por aquello a lo que también podemos obligarles; por consiguiente, la cualidad del hombre de ser su propio señor». Kant, l., Metafísica..., op. cit.., págs. 48/49.

95 Malmofer, W., "Principios de una democracia en libertad", en Benda et alii, Manual..., op. cit., págs. 280/81. 
el diputado Peces-Barba en el debate constituyente, del que se hizo mención, en el sentido de que el texto del art. 10.1. supone el repudio de cualquier concepción transpersonalista y totalitaria adquiere aquí pleno sentido.

Ahora bien, si bien es cierto que la libre determinación personal se materializa en el sistema de derechos reconocidos por la Constitución, dicho sistema no agota en modo alguno su ámbito de actuación. La esfera de la libre determinación comprende, en primer lugar, a los derechos fundamentales y libertades públicas, que vienen a constituir el núcleo primario de materialización de los principios que estamos considerando, y gozan de primacía, lógica y jurídica, sobre los demás; en segundo lugar los derechos meramente constitucionales, esto es, los correspondientes a los arts. 30 y ss CE, que son derechos subjetivos reconocidos por la Constitución, aun cuando no recaiga en ellos la cualidad de ser fundamentales en el sentido del T.I. CE; en tercer lugar los derechos subjetivos de determinación legislativa que dotan de vinculatoriedad a los derechos sociales que en la Constitución encuentran reconocimiento; en cuarto lugar los derechos subjetivos reconocidos por la legislación ordinaria; finalmente la esfera de mero agere licere, que carece de la protección reforzada propia del derecho subjetivo, y que se define por la esfera de acción que comprende aquellas que no estando vedadas por el ordenamiento se hallan entregadas a la disponibilidad del individuo a titulo de acciones permitidas.

Al igual que sucede en el caso de la dignidad el libre desarrollo de la personalidad es un principio ${ }^{96}$. En consecuencia, al igual que en el caso anterior, no estamos en presencia de un derecho fundamental en si mismo considerado ${ }^{97}, \mathrm{ni}$, por tanto, puede fundamentarse recurso de amparo alguno en la eventual lesión de dicho principio ${ }^{98}$. Al igual

96 Creo que tiene razón Prieto Sanchis cuando señala que el inciso de referencia supone la consagración constitucional del principio moral de autonomía, vid. Prieto Sanchis, L., Estudios..., op. cit., pág. 161.

97 Aquí radica una de las diferencias principales entre el sistema de derechos de la CE y el de la Ley Fundamental de Bonn, en el que sí existe tal derecho general.Tal parece como si el constituyente siguiera en esta cuestión el conocido criterio de Dworkin. Vid. Dworkin, R., Los Derechos..., op. cit., págs. 381 y ss. No es casual que los intentos de introducir entre nosotros un derecho general de libertad no se hayan basado en el art. 10.1. CE, sino más bien en un interpretación peculiar de un derecho concreto: la libertad de conciencia del art. 16.1. CE.

98 En las palabras del TC: "Ante todo, habrá que destacar que la norma contenida en el art. 10.1. CE, con independencia de que pueda servir de criterio de interpretación de los derechos fundamentales y libertades públicas en general, no 
que sucede, insisto, con la dignidad el libre desarrollo de la personalidad opera en el sistema constitucional como fuente y origen del entero sistema de derechos constitucionales y de cada derecho en particular. Que ni uno ni otro son derechos propiamente hablando se desprende claramente no sólo de los enunciados del propio art. 10.1., sino también de la ubicación del precepto en el texto constitucional. Pero de su naturaleza principal y su papel de fuente de los derechos constitucionales se sigue, primero, que cualquier lesión a alguno o a algunos de estos comportará necesariamente lesión de los principios mismos; segundo, que opera como un instrumento de interpretación del sistema de derechos; tercero, que se integra en el conjunto de criterios que debe usar el juez constitucional cuando se trate de ponderar derechos constitucionales en conflicto.

En otras palabras, el principio de libertad que aquí se acoge opera en nuestro ordenamiento constitucional a través del sistema de derechos fundamentales, del que constituye parte de su núcleo esencial desde el momento que aquel principio introduce en dicho sistema el concepto clave de la autonomia personal que vertebra todo el Título I de la ley fundamental. Hunde aquí sus raíces un criterio hermenéutico que el Tribunal viene sosteniendo prácticamente desde el inicio de su actividad: el criterio del favor libertatis, del que se sigue el principio de interpretación restrictivas de las reglas limitadoras de derechos fundamentales ${ }^{99}$.

Cuestión distinta es la de la relación entre libre desarrollo de la personalidad y dignidad. A mi juicio no puede decirse que la esfera de acción lícita permitida por la ley unida al ámbito propio de los derechos subjetivos, sean fundamentales o no, que definen la libertad (tanto en términos negativos como positivos) agote el principio de dignidad, que exige determinaciones materiales que exceden de esa esfera de obrar lícito. La dignidad exige la esfera de autodeterminación personal y su

puede servir de base a una pretensión autónoma de amparo, por impedirlo lo dispuesto en el art. $53 \mathrm{CE}$, que permite a los ciudadanos recabar el amparo para la tutela de las libertades públicas y derechos fundamentales, pero limitándolo a los reconocidos en el art. 14...". STC 64/86 FJ 1.

99 Ad exem.: "Se produce, en definitiva, un régimen de concurrencia normativa, no de exclusión, de tal modo que tanto las normas que regulan la libertad como las que establecen límites a su ejercicio son igualmente vinculantes y actúan recíprocamente. Como resultado de esta interacción, la fuerza expansiva de todo derecho fundamental restringe, por su parte, el alcance de las normas limitadoras que actúan sobre el mismo; de ahí la exigencia de que los límites de los derechos fundamentales hayan de ser interpretados con criterios restrictivos $\gamma$ en el sentido más favorable a la eficacia y esencia de tales derechos". STC 159/86 de 12/12 FJ 6. 
protección jurídica, pero en modo alguno se agota en ella. La libre determinación empero es constitutiva de la dignidad personal, por ello me parece que no anda desencaminado Alexy cuando escribe:

Que tal no es el caso lo muestra una mirada a la conexión entre libertad negativa y dignidad de la persona. Esta conexión puede describirse con las siguientes tesis: La libertad negativa es una condición necesaria, pero no suficiente de la dignidad humana, 100

de lo que obviamente se sigue que la dignidad comprende la libre determinación, pero que resulta de mayor ámbito que ésta. En consecuencia no son mutuamente intercambiables ni plenamente subsumibles, la dignidad exigirá siempre la libre determinación, pero exigirá con frecuencia lo que el autor citado denomina complementación mediante principios concretos, de carácter material.

Ahora bien, si la libre determinación no agota la dignidad y esta comprende un plus que va más allá de aquella se entiende sin dificultad que la dignidad puede establecer fronteras al ejercicio lícito de tal determinación personal autónoma, y que las concreciones materiales que exceden de la libre determinación citada puedan tener virtualidad limitante sobre aquella. Es en este punto donde la cláusula del respeto a la ley y a los derechos de los demás viene a insertarse.

\section{FRONTERAS}

Precisamente porque la libertad dimana de la dignidad personal se sigue que el citado "libre desarrollo de la personalidad" no puede ser entendido como un principio que introduzca una concepción de los derechos fundamentales como derechos carentes de límites. Una autodeterminación que no estuviere orientada a fines $y$, por ende, sujeta a norma sería autodestructiva. Con independencia de otra suerte de problemas que acarrearía una ética orientada primaria o exclusivamente sobre el principio de la autorrealización personal, una construcción de ese tipo pronto entraría en colisión con las exigencias propias del principio de dignidad ${ }^{101}$.En todo caso el discurso del art. 10.1. CE es

100 AleXY, R., Teoría..., op. cit., pág. 344.

101 En efecto, la primacía incondicionada de la autorrealización personal exige la reducción a medio de los demás cuando el recurso a estos sea indispensable para dicha autorrealización. Dicha primacía podría ser compatible con las relaciones simbióticas, pero estas reposan precisamente sobre el acuerdo común que autoriza la mutua reducción a objeto para satisfacción de ambos. 
muy otro y una lectura, aun superficial, de su tercer inciso lo revela claramente: los derechos inherentes y el libre desarrollo de la personalidad encuentra una doble frontera: "el respeto a la ley y a los derechos de los demás", de donde se sigue necesariamente que la autodeterminación personal a que se refiere el texto constitucional no viene definida tanto en términos de independencia, cuanto en otros bien distintos: la autonomía personal ${ }^{102}$.

Es probable que este tercer inciso sea el elemento del enunciado constitucional en el que la influencia kantiana sea al tiempo más intensa y más paladina, lo que poco puede extrañar a la vista de los antecedentes germanos del precepto en cuestión, según hemos visto. En efecto, la autodeterminación personal posibilita al hombre realizarse según sus propios criterios, vivir de acuerdo con sus "máximas", pero estas sólo pueden aspirar al reconocimiento cuando satisfagan exigencias que no están entregadas a la disponibilidad del arbitrio individual, para que la "máxima" pueda aspirar al reconocimiento debe sujetarse al imperativo universalizador, lo que exige, a su vez, el reconocimiento y respeto de la autonomía de los demás $y$ su dignidad, y el de las reglas que son su consecuencia:

Por tanto, el derecho es el conjunto de condiciones bajo las cuales el arbitrio de uno puede conciliarse con el arbitrio de otro según una ley universal de la libertad. 103

El paralelo es, como se ve, palmario. Por lo demás la fijación de las fronteras de los derechos en el precepto se inserta plenamente en la tradición liberal, y en él resuenan los ecos de la Declaración de 1789104 .

La frontera se fija mediante una definición formalmente doble: en su ejercicio los derechos fundamentales que provienen de la libertad y organizan la libertad misma se rigen por el arbitrio. del titular, pe-

102 Lo que arrastra una consecuencia intelectual nada desdeñable: el subjetivismo ético está condenado a llevarse mal, cuando no a entrar en colisión, con el discurso constitucional.

103 KANT, I., La metafísica..., op. cit., pág. 39.

104 Art. 3: "La liberté consiste a pouvoir faire tout ce que ne nuit pas a autrui: ainsi, l'exercice des droits naturels de chaque homme n'a de bornes que celles qui assurent aux autres membres de la societé la jouissance de ces memes droits. Ces bornes ne peuvent etre determinées que par la Loin, en DUVERGER, M., Constitutions et Documents Politiques. PUF.Paris.1957, pág. 3. 
ro el uso legítimo de ese arbitrio se detiene, encuentra la frontera de su esfera de acción autónoma, allí donde comienza la propia y asignada a otra persona, en consecuencia mi ejercicio de los derechos constitucionales alcanza hasta el punto donde comienza el ejercicio de dichos derechos por mi prójimo. A ello agrega el enunciado una segunda frontera, el respeto a la ley, $y$ en este punto las cosas son más complejas, pues, en efecto para que una norma jurídica tenga capacidad para surtir virtualidad limitante del ejercicio de derecho fundamental la norma en cuestión debe ser necesariamente conforme a Constitución, debe ser constitucional, tal requisito sólo puede satisfacerse en dos supuestos: de un lado si los propios enunciados constitucionales configuran una restricción (como es el caso de la cláusula de orden público del art. 16.1. CE o de la reunión pacífica y sin armas del art. $21.1 \mathrm{CE})^{105}$ en cuyo caso la restricción es directa; del otro en los supuestos en los que, bien sea de forma expresa, bien sea de forma tácita, la Constitución habilita al legislador para establecer restricciones en función de la protección de bienes constitucionalmente protegidos (ad exem, el supuesto de la reserva de información pública del art. 105.c) CE en relación con el derecho a comunicar y recibir información veraz del art. 20.1. CE) ${ }^{106}$. En rigor la dualidad es en buena medida aparencial puesto que las partes constitutivas de la misma se mueven en distinto plano: mientras que la cláusula del respeto a los derechos es de carácter estrictamente material, la del respeto al Derecho lo es de carácter formal, en cuanto que la norma juridica, al fijar las condiciones de ejercicio de los derechos, codetermina la esfera de acción legitima que a la autonomía de los demás se reserva. En otras palabras, desarrollar los derechos a fin de facilitar su ejercicio supone necesariamente limitar su ejercicio mismo, como ya observaba en su día Locke ${ }^{107}$, es más precisamente por ello tiene sentido la cláusula de contenido esencial del art. 53.1. CE.

En todo caso debe insistirse en que la referencia a la ley no puede entenderse como una referencia a la ley formal, sino a la regla de Derecho, que la ley formal está lejos de agotar, en este punto el texto

105 Una enumeración de los límites constitucionalmente fijados de forma expresa en AguiaR DE LUQUE, L., "Los límites de los derechos fundamentales", RCEC, n. ${ }^{\circ 14}$, Madrid, 1993 pág. 16/17, en nota.

106 Supuesto que vienen a coincidir con los que Alexy denomina restricciones directamente e indirectamente constitucionales. Vid. ALEXY, R., Teoría..., op. cit., págs. 277 y ss.

107 Locke, J., Segundo Ensayo sobre el Gobierno Civil, prf. 129 y ss. Se cita por la edición de J. AbelLÁN, Dos Ensayos sobre el Gobierno Civil, Espasa Calpe, Madrid, 1991, págs. 295 y ss. 
constitucional sí se distancia de la Declaración de 1789 al responder a un concepto de Constitución distinto del revolucionario, y en el que no tiene cabida la noción de la soberanía e inmunidad de la ley ${ }^{108}$. La "ley" del art. 10.1. es la regla de Derecho, y, en especial, aquella que lo es por antonomasia, por constituir la norma primaria del sistema jurídico: la propia Constitución.

En razón de ello las fronteras de los derechos fundamentales deben ser buscadas ante todo en los propios preceptos constitucionales que los configuran, que pueden establecer fronteras específicas en casos concretos (por ejem. vide arts. 16.1. in fine,17.2, 18.2, 20. 2 y 4, CE etc.), en el resto de las normas constitucionales, en el orden axiológico de las mismas, en la moral mínima común que a la Constitución entera subyace y en la naturaleza y presencia de los bienes constitucionalmente protegidos, criterio que es el que viene a seguir el TC:

En efecto, no existen derechos ilimitados. Todo derecho tiene sus límites, que, como señalaba este Tribunal en sentencia de 8 de abril de 1981 (...), en relación a los derechos fundamentales establece la Constitución por sí misma en algunas ocasiones, mientras en otras el límite deriva de una manera mediata o indirecta de tal norma, en cuanto ha de justificarse por la necesidad de proteger o preservar no sólo otros derechos constitucionales, sino también otros bienes constitucionalmente protegidos. 109

Obviamente la determinación de las fronteras y, en su caso, de los límites, viene a plantear un problema práctico de interés evidente: como se articula el juego entre los principios del sistema de derechos, que exigen una vis expansiva de los mismos y conducen a la doctrina ya vista del favor libertatis, y el establecimiento de fronteras y limites formales por parte del mismo texto constitucional, que viene a situar derechos fundamentales y fronteras de los mismos en el mismo plano normativo. La doctrina del TC en la materia gira en torno a dos argumentos fundamentales: primero, la necesidad de justificación de los actos con virtualidad limitante, que conduce lógicamente a la necesidad de motivación de los mismos al efecto de contrastar dicha justificación ${ }^{110}$; segundo, la naturaleza misma de la fronteras, cuya función

108 Vid. Blanco Valdés, R. L., El valor de la Constitución, Alianza Ed., Madrid, 1994, págs. $214 \mathrm{y}$ ss.

109 STC 2/82 FJ 5, cit., entre otras, en STC 57/94 FJ 6.

110 Ad exem.: "Cuando se coarta, como en este caso, el libre ejercicio de los derechos reconocidos por la Constitución, el acto es tan grave que se necesita 
no es comprimir la esfera de acción configurada por el sistema de derechos, sino mas bien determinar cual es su horizonte propio, lo que conduce directamente a la aplicación del escrutinio estricto en la interpretación de dichas fronteras ${ }^{111}$.

La jurisprudencia constitucional en la materia fue en su día duramente criticada por de Otto112 por entender que la misma está condenada a oscilar entre la cláusula de contenido esencial y la ponderación de bienes y valores en presencia, de tal modo que la misma no puede sino debilitar la garantía constitucional de los derechos fundamentales e introducir en la cuestión un grado inaceptable de inseguridad jurídica. La propuesta alternativa consistía en esencia en la inadmisión de otros limites que los constitucionalmente fijados y en buscar la operatividad de los necesarios pero no encuadrables en dicha categoría mediante una mas cuidadosa delimitación del objeto y ámbito de cada derecho fundamental. Como señala con justeza Aguiar de Luque una tesis así peca de formalismo y presume una excesiva facilidad en la operación de delimitación conceptual de cada uno de los derechos. A mi juicio resulta significativo el escaso papel que a la cláusula que comentamos presta la tesis en cuestión, cosa que no ocurre, por cierto, en la propuesta del citado profesor Aguiar ${ }^{113}$. No obstante me parece indisputable que la crítica de referencia tiene la virtud de llamar la atención sobre un riesgo inherente a la construcción: que el TC derive hacia una interpretación excesivamente amplia de la virtualidad limitante que pueda derivarse de la invocación de dichos bienes y valores constitucionalmente protegidos, deriva a la que no es ciertamente ajena la política seguida en la materia por el Tribunal.

encontrar una especial causalización y el hecho o el conjunto de hechos que lo justifican deben explicitarse con el fin de que los destinatarios conozcan las razones por las cuales su derecho se sacrificó y los intereses a los que se sacrificó.De este modo, la motivación no es sólo una elemental cortesía, sino un riguroso requisito del acto de sacrificio de los derechos». STC 26/81 FJ 13.

111 Ad exem.: "Se produce, en definitiva, un régimen de concurrencia normativa, no de exclusión, de tal modo que tanto las normas que regulan la libertad como las que establecen límites a su ejercicio son igualmente vinculantes y actúan recíprocamente.Como resultado de esta interacción, la fuerza expansiva de todo derecho fundamental restringe, por su parte, el alcance de las normas limitadoras que actúan sobre el mismo; de ahí la exigencia de que los límites de los derechos fundamentales hayan de ser interpretados con criterios restrictivos y en el sentido más favorable a la eficacia y esencia de tales derechos". STC 159/86 FJ 6

112 Vid. Martin-Retortillo, L. y de Otto Pardo, I., Derechos fundamentales y Constitución, Civitas, Madrid, 1988 ese., pág. 124 y ss.

113 Aguiar de LuQue, L., Los limites..., op. cit., págs. 27 y s. 
Que la cláusula constitucional comporta la aceptación de la idea de que los derechos tienen límites propios, inmanentes, me parece obvio, que la misma viene a significar que estos límites inmanentes no son los únicos también, pues de otro modo la invocación del respeto a la ley que la cláusula contiene quedaría vacía de sentido y reducida a mera retórica constitucional, hipótesis a excluir por obvios motivos metodológicos. La tesis sostenida por Aguiar, a saber que tales bienes y valores deben ser determinados con ayuda de las cláusulas que los documentos a que se refiere el art. 10.2. CE contienen al efecto de precisar que bienes y valores pueden tener virtualidad limitante y cuales no (la conocida cláusula de las medidas necesarias en una sociedad democrática del CEDH, o la citada por Aguiar, el art. 29.2. DUDH), merece una detenida atención.

\section{LOS DERECHOS FUNDAMENTALES COMO ORDENAMIENTO OBJETIVO}

Si en algún punto la concepción del sistema de derechos fundamentales propia del texto constitucional español de 1978 se separa del individualismo típico de la tradición liberal clásica e introduce una concepción específicamente democrática de aquellos ese, sin duda, viene dado por el inciso final del apartado primero del art. 10. CE cuando dicho precepto establece que los principios de dignidad y libertad y los derechos constitucionales que son su consecuencia son

fundamento del orden político y de la paz social.

Por de pronto hay que remarcar que al situar a los derechos constitucionales como "fundamento" de la sociedad civil y la comunidad política el texto constitucional viene a reforzar una afirmación previa ya anotada, a saber, que los derechos constitucionales son, cuanto menos lógicamente, anteriores al orden social y político, pues de otro modo mal podría operar tales derechos como "fundamento" de nada. En consecuencia mediante el presente enunciado se viene a reforzar una tesis que ya se ha apuntado, aquella en virtud de la cual el art. 10.1. CE comportan una remisión a un ordenamiento, a una regulación prepositiva, que fundamenta, y limita, al legislador y a las normas que este puede producir. Se sigue, por tanto, que cualquier reconstrucción doctrinal que aspire a ser utilizable a los efectos de la interpretación constitucional debe ser necesariamente compatible con el presente 
postulado, pues, de otro modo, no ve como podria dar respuestas coherentes a cuestiones tales como los problemas derivados del concurso de derechos fundamentales o los que proceden de la cláusula de contenido esencial. Y ello con independencia de la opinión que se tenga acerca de la posible introducción en nuestro ordenamiento de la doctrina del BVfG a partir de caso Lüth, fundada a su vez en el precepto homólogo del art. 1.2. GG que es, por demás, aceptada por la mayor parte de la doctrina y cuyos ecos resuenan en al menos algunas decisiones constitucionales, según la cual, los derechos fundamentales, a más de asegurar esferas de libertad individual implican un orden axiológico, un sistema de valores, que rige en el conjunto del ordenamiento ${ }^{114}$.

En todo caso el enunciado del inciso final del art. 10.1. CE viene a establecer que aun antes de su configuración como derechos en el sentido estricto de la expresión, los derechos constitucionales son parte del orden vinculante de convivencia prescrito por la Constitución misma.En consecuencia tales derechos no se limitan a garantizar esferas de autonomía a los titulares (o, en su caso, les habilitan para exigir prestaciones a los poderes públicos), antes bien, si puede configurar derechos públicos subjetivos y definir obligaciones de hacer cuyo destinatario es el Estado ello se debe a que integran el ordenamiento objetivo de ese mismo Estado, del cual son un componente esencial, por eso la doctrina habla de la "vertiente objetiva" de los derechos fundamentales ${ }^{115}$, tesis que, a la postre, viene aceptada de antiguo por el TC, del que es doctrina pacífica ${ }^{116}$. Los derechos constitucionales devienen

114 Ad exem.: "Los derechos y libertades fundamentales son elementos del ordenamiento, están contenidos en normas jurídicas objetivas que forman parte de un sistema axiológico positivizado por la Constitución y que constituyen los fundamentos materiales del ordenamiento jurídico entero (véanse los arts. 1.1, 9.2, 10.1, y 53 de la Constitución). Por ello pienso que sería nula de pleno derecho, no sólo en base a los artículos 6.3 y 1255 del CC, sino en virtud de los citados preceptos constitucionales, cualquier cláusula de un contrato laboral en la que el profesor se comprometiera a renunciar de antemano a ejercer en sentido determinado cualquier derecho o libertad fundamental en atención al ideario del centro". STC 5/81 de 13/2 (Voto particular).

115 Ad exem.: Fernández Segado, F., La teoría..., op. cit., pág. 209.

116 Ad exem.: "Los derechos fundamentales son derechos subjetivos, derechos de los individuos no sólo en cuanto ciudadanos en sentido estricto, sino en cuanto garantizan un status jurídico o la libertad en un ámbito de la existencia. Pero, al propio tiempo son elementos esenciales de un ordenamiento objetivo de la comunidad nacional, en cuanto ésta se configura como un marco de convivencia humana justa y pacífica, plasmada históricamente en el Estado social de Derecho o el Estado social y democrático de Derecho, según la formula de nuestra Constitución (art. 1.1). Esta doble naturaleza de los derechos fundamentales, desarrollada por la doctrina, se recoge en el art. 10.1. de la Constitución (FJ 5)". STC 25/81 de 14/7. 
así lo que el TC ha denominado "componentes estructurales básicos" del ordenamiento general y de todas y cada una de sus ramas, como viene a señalar el Tribunal en un texto ampliamente citado en la jurisprudencia posterior:

Los derechos fundamentales no incluyen solamente derechos subjetivos de defensa de los individuos frente al estado, y garantías institucionales, sino también deberes positivos por parte de éste (....). Pero, además, los derechos fundamentales son los componentes estructurales básicos, tanto del orden jurídico objetivo como de cada una de la ramas que lo integran, en razón de que son la expresión jurídica de un sistema de valores, que, por decisión del constituyente, han de informar el conjunto de la organización jurídica y política; son, en fin, como dice el art. $10 \mathrm{CE}$ el ufundamento del orden jurídicos $y$ de la paz social», 117

puede estimarse poco acertado el exclusivo énfasis en la fundamentación axiológica, que, como veremos, no es la única, pero no cabe duda que tan contundente toma de posición es coherente con el texto de la ley fundamental misma, y viene a situar al sistema de derechos de la Constitución en una perspectiva bien diferente a la propia de la tradición individualista propia de liberalismo clásico. En razón de esa condición de "componentes estructurales básicos" el Tribunal viene a afirmar, con razón, que los derechos en cuestión son un "valor central» 718 en el ordenamiento ¿como podría ser de otro modo si lo fundamentan? No está de más precisar aquí una consecuencia obvia: si los derechos constitucionales son componentes necesarios del ordenamiento se sigue necesariamente que las relaciones inter-privatos entran dentro de su campo de aplicación y que, por tanto, son derecho válido y eficaz en lo que a dichas relaciones entre particulares afecta, cosa que, por demás, es poco menos que la única interpretación coherente con el enunciado de otro precepto constitucional clave: el art. 9.1. CE, que precisa que las normas constitucionales vinculan no sólo a los poderes públicos, sino también a los ciudadanos ${ }^{119}$.

117 STC 53/85. FJ 4.

118 Ad exem: "Lo que nos lleva a la conclusión de que la admisión de la moral pública como límite ha de rodearse de las garantias necesarias para evitar que bajo un concepto ético, juridificado en cuanto mínimum ético para la vida social, se produzca una limitación injustificada de derechos fundamentales y libertades públicas, que tienen un valor central en el sistema jurídico (art. $10 \mathrm{CE}$ )». STC $62 / 82$ FJ 3 B).

119 Por lo demás, suscribo en este punto la posición sostenida por PecesBarba, vid. Curso..., op. cit., págs. 624 y ss. 
Mas existe una segunda razón que abona la tesis de la centralidad,que se encuentra encerrada en la afirmación tópica del «derecho objetivo" y se halla más próxima al enunciado del propio texto constitucional. Si los derechos constitucionales son "fundamento" del orden político se sigue que el orden político democrático, que es el orden político de referencia en el texto constitucional (cf. art. 1.1 y 2. CE), exige la eficacia plena de tales derechos para existir como tal, que tales derechos tienen, en consecuencia, un papel institucional de primera magnitud, en cuanto que sin su plena virtualidad el orden político-constitucional sencillamente no existiría porque fallarían buena parte de sus presupuestos. Ciertamente puede alegarse que ese "papel institucional" es más relevante en unos derechos fundamentales que en otros (piénsese en la referencia tradicional a los derechos de expresión, reunión y asociación) en tanto en cuanto hay una relación más estrecha entre sistema democrático y determinados derechos que con los demás. Pero mayor inmediación sólo implica necesidad más directa, esta puede no ser jurídicamente irrelevante, pero lo que no puede entenderse en modo alguno es que el resto de los derechos constitucionales no se hallen en la condición mencionada porque su grado de inmediación sea menor. La mayor inmediación puede justificar la atribución a determinados derechos de una posición particular, pero nada más ${ }^{120}$.

Adicionalmente si el sistema de derechos constituye una parte, un componente, del orden vinculante de convivencia prescrito por la Constitución se sigue necesariamente que, como ya apuntara el Voto Particular de la sentencia sobre la LOECE, los derechos fundamentales son un componente nuclear, esencial del «orden público protegido por la (ey), al que se refiere, por ejemplo, el art. 16.1. CE, tesis por demás avalada por la jurisprudencia del propio TC ${ }^{121}$. Mas si el sistema de derechos fundamentales integra el orden público los derechos que del mismo forman parte también lo hacen y, en consecuencia, están retirados del dominio entregado por el ordenamiento a la autonomía de la voluntad, resultando por ello indisponibles.

120 En efecto, el "papel institucional» es uno de los argumento usados por el TC para determinar si un determinado derechos fundamental goza o no de "posición preferente". Martínez Sospedra, M., Libertades..., op. cit., págs. 62 y ss.

121 Ad exem.: "... aunque es evidente que el respeto a los derechos fundamentales y libertades públicas garantizados por la Constitución es un componente esencial de orden público, y que, en consecuencia, han de tenerse por nulas las estipulaciones contractuales incompatibles con este respeto...". STC 19/85 FJ 1. 
Además conviene resaltar que en la economía del art. 10.1. CE los derechos constitucionales viene concebidos primariamente como elementos fundamentadores del Estado democrático de Derecho, del cual son, en primer lugar, un principio estructural, en segundo lugar un componente esencial, en tercer lugar una condición necesaria, y ello de tal modo que la prioridad lógica del sistema de derechos se traduce en este caso $y$ en este punto en un presupuesto material: sencillamente las instituciones que definen como democrático a un Estado Constitucional son impensables sin la preexistencia de un sistema de derechos efectivo. Lo que, a la postre, no es sino otra forma de señalar que si bien un Estado Constitucional puede no ser democrático, un Estado Democrático no tiene otra opción que ser Constitucional, so pena de desmentirse a sí mismo. Razón por la cual no es un mal indicador de la salud democrática de los Estados el indagar acerca de la sustantividad de su sistema de derechos. Los derechos fundamentales son, pues, tanto una parte del Estado democrático ${ }^{122}$ cuanto una parte del orden vinculante de convivencia por la ley fundamental prescrito, del orden constitucional ${ }^{123}$.

Ahora bien, si el sistema de derechos es parte del orden constitucional e integran el derecho objetivo se sigue de ello no sólo que tienen a la comunidad y a sus miembros como destinatarios de sus mandatos (como explicita el art. 9.1. CE, por cierto), sino también al menos otros dos tipos de consecuencias: de un lado los derechos constitucionales no pueden entenderse sencillamente como un conjunto de mandatos dirigidos a los poderes públicos. En tanto en cuanto definen el orden vinculante de convivencia e integran el orden publico vinculan también a los ciudadanos, tanto en lo que se refiere a las relaciones entre estos y los poderes públicos cuanto en lo que afecta a las relaciones inter privatos que los ciudadanos mismos puedan establecer ${ }^{124}$. Di-

122 Ad exem.: "En un segundo aspecto, en cuanto elemento fundamental de un ordenamiento objetivo, los derechos fundamentales dan sus contenidos básicos a dicho ordenamiento, en nuestro caso al del Estado social y democrático de Derecho, y atañen al conjunto estatal... Puede decirse que los derechos fundamentales, por cuanto fundan un status jurídico-constitucional unitario para todos los españoles y son decisivos en igual medida para la configuración del orden democrático... son elemento unificador...". STC 25/81 FJ 5.

123 Ad exem.: "...es decir, desde otra perspectiva del orden constitucional, ya que tales libertades y derechos son el fundamento del orden político y de la paz social, junto con la dignidad de la persona humana, el libre desarrollo de la personalidad y el respeto a la Ley y a los derechos de los demás". STC 2/82 FJ 3.

124 Ad exem.: "Esta concretización de la Ley suprema no debe interpretarse en el sentido de que sólo se sea titular de los derechos fundamentales y liberta- 
cha conclusión, dimanante por lo demás del citado art. 9.1. CE, encuentra en el inciso final del art. 10.1. CE su fundamentación normativa.

Finalmente, si el sistema de derechos es parte de derecho objetivo ex art. 10.1. CE se siguen para el Estado al menos tres tipos de deberes que aquel debe satisfacer tanto respecto del sistema mismo cuanto de los derechos constitucionales que lo integran:

Primero. Un deber de protección, en virtud del cual el Estado tiene el deber $-y$ los ciudadanos sean o no titulares, en cuanto interesados, el derecho- de establecer un sistema de protección eficaz de los derechos y de su libre ejercicio por parte de los titulares. Deber de protección que exige extraer las consecuencias debidas de la naturaleza antijurídica de las acciones y omisiones que vulneren o menoscaben los derechos constitucionales, y que incluye no sólo el desempeño de las tareas públicas o el suministro de los bienes y servicios que sean necesarios para asegurar el disfrute efectivo de dichos derechos, sino también la tipificación como ilícitos de las conductas lesivas correspondientes, con inclusión, como ya se señaló de la tipificación penal de tales ilícitos.

Segundo. Un deber de respeto, en virtud del cual el Estado viene obligado a abstenerse de cualquier tipo de conducta que vulnere o menoscabe cualquiera de los derechos constitucionales, deber que no se satisface meramente con la producción de normas conforme a Constitución, sino que exige un especial cuidado para no menoscabar derechos constitucionales bien sea por vía de interpretación de las normas, bien sea por vía de la aplicación de las mismas. Deber de respeto a cuya satisfacción responde, por cierto, la figura del Defensor del Pueblo prevista por el art. $54 \mathrm{CE}$, así como las figuras semejantes creadas en las Comunidades Autónomas.

Tercero. Un deber de promoción, o de fomento, que corresponde a los poderes públicos, bien sea de oficio, bien a incitación del ciudadano, que exige de estos la adopción de normas, medidas y actos destinados a facilitar a los titulares el pleno ejercicio de los derechos constitucionales ${ }^{125}$, y que dimana no sólo del principio general

des públicas en relación con los poderes públicos, dado que en un estado social de derecho como el que consagra el art. 1. de la Constitución no puede sostenerse con carácter general que el titular de tales derechos no lo sea en la vida social...n. STC18/84 FJ 6.

125 Ad exem.: "De la significación y finalidad de estos derechos dentro del orden constitucional se desprende que la garantía de su vigencia no puede limitarse 
que comentamos, sino también del especifico deber configurado al efecto por el art. 9.2. CE, que no es sino el complemento del presente enunciado.

\section{LA CLÁUSULA HERMENÉUTICA}

El apartado segundo del art. 10. CE es un precepto que carece de paralelo en el derecho constitucional de los paises de nuestro entorno, con la muy parcial excepción portuguesa de que se hizo mención. Aunque su razón remota obedezca a una determinada intencionalidad política, el dato relevante es el de la incidencia permanente sobre el sistema de derechos constitucionalmente consagrado, incidencia que excede ampliamente aquella intencionalidad. Que el art. 10.2. encierra una cláusula hermenéutica es algo que se evidencia por el mismo texto, $y$ que tiene expresa consagración en el debate constituyente operado en la Asamblea en la que el texto se vino a introducir, esto es el Senado ${ }^{126}, y$ que ha tenido reconocimiento expreso por la jurisprudencia del TC ${ }^{127}$. Que dicha cláusula supone una autovinculación operada ex Contitutione en beneficio de las normas internacionales es una afirmación que a fuerza de frecuente se ha tornado tópica ${ }^{128}$. No obstante lo cual el precepto no deja de plantear problemas.

Vaya por delante que el art. 10.2. CE nada nos dice acerca de estatuto de los tratados en nuestro Derecho, esa es cuestión que afrontan

a la posibilidad de ejercicio de pretensiones por parte de los individuos, sino que tiene que ser asumida también por el Estado. Por consiguiente, de la obligación de sometimiento de todos los poderes a la Constitución no solamente se deduce la obligación negativa del Estado de no lesionar la esfera individual o institucional protegida por los derechos fundamentales, sino también la obligación positiva de contribuir a la efectividad de tales derechos, y de los valores que representan, aun cuando no exista una pretensión subjetiva por parte del ciudadano". STC 53/85 FJ 4.

126 En efecto: "Y ello (10.2.) a fin de definir en el futuro la más precisa comprensión e interpretación de las libertades y derechos explicitados en los artículos siguientes". EsCUDERo LóPEZ, DSCCS, 23/8/78, pág. 1739.

127 Ad exem.: "De acuerdo con este precepto (10.2.), la Constitución se inserta en un contexto internacional en materia de derechos fundamentales y libertades públicas, por lo que hay que interpretar sus normas en esta materia de conformidad con la Declaración Universal de Derechos Humanos y los tratados y acuerdos internacionales sobre la materia ratificados por Españas. STC 62/82 FJ 2.

128 Así vid. SÁnchez FerRiz, R., Estudios sobre las libertades, 2.a ed., Tirant lo Blanch, Valencia, 1995, pág. 148 y ss.; López GuerRA, L. et alii, Derecho Constitucional, 2 V, V. I, Tirant lo Blanch, Valencia, 1994, págs. 140 y ss. Torres Del Moral, A., Principios de Derecho Constitucional Español, 3.a ed., 2 v. A, tomo, Madrid, 1992, v. I, págs. 380 y s., o Peces-Barba et alii, Curso..., op. cit., págs. 407 y ss. 
y resuelven los arts. 95 y ss. CE, en virtud de los cuales los tratados se integran el ordenamiento español simplemente con su válida ratificación y publicación, que constituyen norma inmune al legislador, que puede desarrollarlos $y$ aplicarlos, pero no modificarlos o privarlos de vigencia y que, al menos un vez integrados en nuestro ordenamiento, tienen plena capacidad innovativa y puede fundamentar pretensiones válidas ante las administraciones públicas y los tribunales. Todo ello ni afecta a las reglas del art. 10.2., ni resulta afectado inmediatamente por estas. El art. 10.2. se mueve en otro plano.

El alcance específico del precepto resulta diáfano al surgir inmediatamente del enunciado mismo:

Las normas relativas... se interpretarán...

Nos encontramos pues ante una suerte de precepto paralelo a las reglas de los arts. 3 y s. CC, mediante el cual se impone a los operadores jurídicos un determinado instrumento de interpretación, cuyo uso deviene necesario en virtud del precepto mismo, y cuyo campo de aplicación aparece prima facie en términos de sistema de derechos.

En cuanto tal cláusula la del art. 10.2.CE plantea implícitamente la cuestión de la congruencia principial entre el sistema de derechos de la Constitución y los instrumentos de referencia, pues va de suyo que si aquella congruencia no se produce la aplicación del canon hermenéutico prescrito puede conducir a conclusiones aberrantes.Tal presupuesto se satisface en el presente caso, pues tanto la Declaración Universal, como el PIDCP o el PIDESC basan los respectivos sistemas de derechos en principios similares a los que acoge el art. 10.1. CE, al efecto basta considerar que el primer párrafo del Preámbulo de la Declaración Universal reza:

Considerando que el reconocimiento de la dignidad inherente a todos los miembros de la familia humana y sus derechos iguales e inalienables constituye el fundamento de la libertad, de la justicia $y$ de la paz en el mundo. ${ }^{129}$

129 Merece señalarse que en la Declaración el sujeto que se ínvoca es el "ser humano" o, como dice el texto transcrito los "miembros de la familia humana", eludiendo cuidadosamente definir al titular de tales derechos en términos de persona. 
Fórmula muy similar se encuentra en el Preámbulo del PI$D S^{130}, y$, a su vez, una virtualmente idéntica se halla en el primer párrafo del Preámbulo del PIDC.

\section{a) El problema del ámbito}

El bloque normativo al que es de aplicación el particular canon hermenéutico que aquí se comenta viene descrito en el primer inciso del enunciado constitucional en los siguientes términos:

Las normas relativas a los derechos fundamentales y a las libertades que la Constitución reconoce...

El inciso merece, cuanto menos, dos observaciones: en primer lugar su objeto abarca la intelección de los preceptos constitucionales que configuran el sistema de derechos, pero no se reduce a estos; en segundo lugar que su campo de aplicación parece ceñirse al ámbito de los derechos fundamentales y libertades públicas y no a la totalidad del sistema de derechos reconocidos por la ley fundamental, aunque el precepto no resulte en este punto todo lo claro que sería deseable. Mas vayamos por partes.

Por lo que a la primera cuestión afecta resulta paladino que el precepto resulta de aplicación a las normas constitucionales que integran el sistema de derechos, pero me parece razonable sostener que, en contra de lo que suele ser tesis corriente, el ámbito de aplicación de la norma hermenéutica no se reduce a aquellas. En efecto, el tenor literal del precepto se refiere no a las normas que reconocen derechos en la Constitución misma, sino a aquellas que contienen regulación de tales derechos y su ejercicio (... relativas a los derechos...), es decir el campo de aplicación no se reduce a las normas de la declaración constitucional de derechos, sino que se extiende cuanto menos a la producción normativa subconstitucional que a su amparo se produzca. De este modo el precepto vendría a exigir la aplicación del citado canon no

130 Cuyo primer párrafo reza así: "Considerando que, de conformidad con los principios establecidos en la Carta de las Naciones Unidas, el reconocimiento de la dignidad inherente a los miembros de la familia humana y de sus derechos iguales e inalienables constituye el fundamento de la libertad, Ja justicia y la paz en el mundo". 
sólo a la parte correspondiente de la Constitución, sino también a sus normas de desarrollo y aplicación a fin de procurar la extensión a todo el bloque normativo regulador del sistema de derechos la garantía que dicho canon comporta.

En cuanto a la segunda cuestión resulta evidente que hay una coincidencia incompleta entre el enunciado del inciso y el encabezamiento de la sección primera del capítulo segundo, pero también lo es que el precepto no se halla inserto en dicha sección, que constituye el pórtico de la declaración de derechos y que se ubica junto a un encabezamiento también parcialmente coincidente $y$ significativamente más amplio: derechos y deberes fundamentales. La cuestión que el texto deja abierta se puede exponer en los siguientes términos: ¿la cláusula se aplica a los derechos fundamentales y libertades públicas exclusivamente o se extiende más allá, comprendiendo los restantes derechos constitucionales?, el criterio sostenido por la doctrina, y el asumido tácitamente por el TC, coinciden en limitar el ámbito a los derechos y libertades de la sección primera del capítulo II del T.II CE. Tal criterio restrictivo, que viene a excluir del ámbito de la cláusula algunos derechos constitucionales cuya cobertura internacional no es desdeñable, (el derecho a adoptar medidas de conflicto colectivo o el derecho a la negociación colectiva, por ejemplo, vide art. $37 \mathrm{CE}$ ) no parece coherente con el telos del precepto ${ }^{131}$, de tal modo que me parece preferible la interpretación del enunciado en el sentido de comprender todos los derechos constitucionales en el sentido propio y estricto del términos, con inclusión de los de la sección segunda del Capitulo II, esto es los derechos meramente constitucionales.

\section{b) Las normas de referencia}

Al efecto de precisar el sentido de las normas constitucionales de que se ha hecho mención el texto de referencia nos remite a un conjunto de documentos internacionales determinados por el juego entre una referencia expresa y una remisión. La referencia expresa cita a la Declaración Universal de los Derechos del Hombre, la cláusula de re-

131 Escribe Fernández Segado: «En principio hay que ver en el art. 10.2 de la Constitución, como muestra a las claras su origen y génesis en el iter constituyente, una cláusula de tutela y garantía de los derechos, enderezada a salvar las dificultades de interpretación de los derechos constitucionalmente reconocidos, recurriendo al efecto a las normas de los tratados internacionales en materia de derechos humanos". Vid. Fernández Segado, F., La teoría..., op. cit., págs. 225/6. 
misión lo hace a los tratados y convenios internacionales sobre las materias propias del ámbito en los que España sea parte. La determinación de las normas de referencia nos sitúa ante una leve paradoja: la prioridad léxica que el precepto da la Declaración es indudable, pero, a diferencia de los Tratados y Convenios, que son en pleno sentido del términos Derecho Internacional, esto es, Derecho, y que,además, mediante su ratificación por España se convierten en Derecho inmediatamente vigente en nuestro país como parte del nuestro propio ordenamiento, la citada Declaración no es otra cosa que una Resolución de la Asamblea General de las Naciones Unidas, cuya calidad técnica es tan elevada como evidente, y cuya autoridad moral es muy grande, pero cuya eficacia jurídica directa es inexistente. Es más, sólo si se entiende la Declaración como un documento que sistematiza normas de Derecho Internacional General podemos tener la seguridad de que la Declaración misma es Derecho. Pese a lo cual la Constitución da cierta prioridad a la Declaración sobre los demás textos.

Vistas las cosas desde una perspectiva material la leve paradoja apuntada se disuelve fácilmente en tanto en cuanto tengamos en cuenta que la inmensa mayoría de los tratados y convenios sobre dichos derechos y libertades ratificados por España son textos sucesores de la Declaración, a la que vienen a desarrollar $y$, en ocasiones, completar, de tal modo que en conjunto, no sería exagerado decir que forman un sistema integrado ${ }^{132}$.

En la práctica la cláusula se utiliza primariamente al efecto de integrar las disposiciones CEDH, y en su estela la jurisprudencia del TEDH, con los preceptos constitucionales al efecto de precisar su sentido. Las razones de esa preferencia - doctrina y jurisprudencial - por el TEDH son sustancialmente tres: primera, se trata de una norma regional más próxima a nuestra realidad, que fue muy tenida en cuenta por los constituyentes y constituye un precedente próximo del sistema constitucional de derechos; segunda, al estar el CEDH permanentemente actualizado merced a la jurisprudencia del TEDH, la referencia próxima resulta ser, al tiempo la mas detallada, flexible y concreta; tercera, al ser España estado que ha reconocido la jurisdicción del TEDH en los términos del art. 46 del Convenio, la referencia al CEDH y a la ju-

132 La doctrina suele centrar sus referencias, a más de en la Declaración, en el Convenio de Roma, en el Pacto Internacional de Derechos Civiles y Políticos, el Pacto Internacional de Derechos Económicos, Sociales y Culturales y la Carta Social Europea, de los cuales el instrumento más invocado es, sin duda el CEDH. EI TC por su parte agrega a ese repertorio algunos convenios OIT. 
risprudencia del TEDH -que son derecho español ambos ex art. 96 CE - constituye la primera operación lógica, de tal modo que si su invocación basta para la resolución de la cuestión interpretativa planteada generalmente se entiende alcanzada la solución y la operación se da por concluída sin necesidad de posterior invocación de otros instrumentos.

\section{c) La significación de la cláusula}

Como ya se ha señalado, el constituyente introdujo el actual art. 10.2. CE para asegurar una interpretación del sistema de derechos particularmente garantista y evitar, con ello, que se pudiera introducir lícitamente interpretaciones reduccionistas del ámbito de libertad reconocido y protegido por cada derecho fundamental. En consecuencia el precepto implica, como señala Álvarez Conde ${ }^{133}$, una prevalencia de principio del precepto constitucional afectado en cada caso sobre los instrumentos internacionales, solo utilizables en este contexto a titulo de instrumento interpretativo.

No obstante la cláusula reposa sobre un supuesto implícito: que el conjunto de los instrumentos de referencia comporta un grado de protección y garantía de las esferas de autodeterminación que los distintos derechos constitucionales protegen al menos igual, sino mayor, que el que se obtendría mediante una recta interpretación de los derechos constitucionales, de tal modo que, mediante el art. 10.2. y su canon hermenéutico forzoso el constituyente trata de sostener un elevado standard de derechos constitucionales, cerrando la puerta a interpretaciones reductoras de aquellos ámbitos de libertad. En lineas generales el supuesto implícito se satisface, bien porque el standard es común al texto constitucional y los de referencia, bien porque estos contienen disposiciones que orientan en sentido garantista al legislador español (por ej. la libertad religiosa y de cultos), bien porque el instrumento internacional por sí mismo viene a dotar de una garantía más fuerte a un derecho constitucional determinado (por ejemplo el art. 17.1. CE en relación con el art. $5 \mathrm{CEDH}$ ), bien porque el texto de referencia viene a cubrir una laguna dejada por la declaración constitucional (como sucede con el derecho a la vida privada del art. 8.1.CEDH en relación con el art. $18 \mathrm{CE}$ ). Ahora bien, cabe la posibilidad de que tal coincidencia no se dé, bien porque el texto constitucional español in- 
troduzca una innovación no prevista ni recogida en los textos de referencia (por ejemplo art. 18.4. CE, que entraña un derecho fundamental y no una mera garantía institucional según el TC) ${ }^{134}$, bien porque el grado de protección que el texto constitucional otorga a los intereses protegidos mediante el derecho constitucional es mayor (por ejemplo cf art. 6.4. CSE con el art. 28.2. CE). En tales supuestos el uso de los textos de referencia a efectos de interpretación deviene imposible: en el primer supuesto por ausencia de referente, en el segundo porque el telos del precepto lo veda.

Ahora bien, el alcance del precepto no va más allá del que le da el constituirse como instrumento de uso preceptivo al efecto de la interpretación de los concretos preceptos constitucionales declarativos de derechos y libertades. El precepto obliga al operador jurídico a precisar el sentido de los preceptos constitucionales integrando el enunciado constitucional y el o los correspondientes de los textos de referencia que resulten pertinentes, conformando de este modo un bloque normativo cuyo conjunto indica el sentido del enunciado constitucional, no supone, por tanto, una cláusula de remisión normativa mediante la cual se incorpore al Derecho Constitucional español el contenido de los textos de referencia135, con lo cual, al no producirse la incorporación de aquellos a la Declaración de Derechos, resulta evidente que no cabe infracción constitucional directa por lesión de preceptos de los textos de referencia. EI TC así lo ha entendido cuando senala:

Tampoco puede entenderse autónomamente infringido por el precepto cuestionado el art. 10.2. CE, pues esta norma se limita a establecer una conexión entre nuestro propio sistema de derechos fundamentales y libertades, de un lado, y los Convenios y Tratados Internacionales sobre las mismas materias en que España sea parte, de otro.No da rango constitucional a los derechos y libertades internacionalmente proclamados en cuanto no estén también consagrados por nuestra propia Constitución, pero obliga a interpretar los correspondientes preceptos de ésta de acuerdo con el contenido de dichos Tratados o Convenios, de modo que en la práctica este contenido se convierte en cierto modo en el contenido constitucionalmente declarado de los derechos y libertades que enuncia el capítulo segundo del Titulo I de nuestra Constitución.Es evidente, no

Cf. STC 254/93 FJ 6.

135 Como es bien sabido, esa precisamente es una de las hipótesis que se barajaron al inicio del proceso constituyente, y es la posición por la que optaba el art. 1. de la LRP. 
obstante, que cuando el legislador o cualquier otro poder público adopta decisiones que, en relación con uno de los derechos fundamentales o las libertades que la Constitución enmarca, limita o reduce el contenido que al mismo atribuyen los citados Tratados o Convenios, el precepto constitucional directamente infringido será el que enuncia ese derecho o libertad, sin que a ello añada nada la violación indirecta y mediata del art. 10.2. CE, que por definición no puede ser nunca autónoma, sino dependiente de otra, que es la que este Tribunal habrá de apreciar en su caso. ${ }^{136}$

La consecuencia lógica, si el precepto se limita a establecer una conexión, pero no convierte en derecho fundamental el enunciado correspondiente de uno o varios textos de referencia, resulta ser que no es factible fundamentar un recurso de amparo en la infracción del art. 10.2. CE: si en tanto que norma de conexión el precepto no es autónomo, sino relacional, la infracción del precepto tampoco puede ser autónoma $y$, en consecuencia, no cabe recurso de amparo si no es fundamentado en infracción de precepto constitucional que tenga atribuida la protección jurisdiccional que se alcanza mediante el uso de dicho instrumento procesal137.

136 STC 36/91 de 14/2 FJ 5.

137 Ad exem.: "En suma, desde un perspectiva formal, la pretensión cuyo fundamento inmediato es el art. 10.2. no resulta aquí viable con carácter autónomo, aun cuando por ser denominador común de todos los derechos fundamentales, contribuyendo a su configuración y ayudando a su entendimiento, habrá de ser tenido en cuenta para valorar aspectos específicos del Auto impugnado...». STC 223/93 FJ 1. 